\title{
A review on potential of biohydrogen generation through waste decomposition technologies
}

\author{
Yee Ho Chai ${ }^{1}$ • Mustakimah Mohamed ${ }^{1} \cdot$ Yoke Wang Cheng ${ }^{1} \cdot$ Bridgid Lai Fui Chin ${ }^{2} \cdot$ Chung Loong Yiin ${ }^{3}$. \\ Suzana Yusup ${ }^{1,4} \cdot$ Man Kee Lam $^{1,4}$
}

Received: 9 September 2020 / Revised: 23 January 2021 / Accepted: 26 January 2021

(C) The Author(s), under exclusive licence to Springer-Verlag GmbH, DE part of Springer Nature 2021

\begin{abstract}
This article reviews various waste decomposition technologies composed of thermochemical and biochemical conversion routes for the generation of biohydrogen from biomass wastes. Due to the escalation of global energy consumptions, concerns on the energy security fuelled increasing generation of energy processes to meet such demands. The development of hydrogen has always sustained interest due to its immense prospects as a clean energy source. Instead, the current hydrogen production process termed as grey hydrogen posed the main contributing factor for carbon-related emissions. Therefore, technological prospects for green hydrogen (biohydrogen) production in the transition towards a decarbonised energy sector are desirable and advantageous. Furthermore, current constraints associated to the production of biohydrogen, ranging from safety to transportation aspects, are also discussed to provide informative insights to researchers and decision makers for a better understanding of biohydrogen economy.
\end{abstract}

Keywords Biohydrogen; · Thermochemical conversion; · Biochemical conversion; · Decarbonisation; · Waste decomposition; · Green technology

\section{Introduction}

Primary energy sources comprise energy sources abundantly available in natural environment that are easily accessible to be harnessed directly. These energy sources are derived from fossil fuels, nuclear fuels, sun, wind, tidal energy, wave energy and geothermal energy. At present, fossil fuels constitute

Suzana Yusup

drsuzana_yusuf@utp.edu.my

1 HICoE-Centre for Biofuel and Biochemical Research, Institute of Self-Sustainable Building, Department of Chemical Engineering, Universiti Teknologi PETRONAS, 32610 Seri Iskandar, Perak, Malaysia

2 Department of Chemical Engineering, Faculty of Engineering and Science, Curtin University Malaysia, CDT 250, 98009 Miri, Sarawak, Malaysia

3 Department of Chemical Engineering and Energy Sustainability, Faculty of Engineering, Universiti Malaysia Sarawak (UNIMAS), 94300 Kota Samarahan, Sarawak, Malaysia

4 Department of Chemical Engineering, Universiti Teknologi PETRONAS, 32610 Seri Iskandar, Perak, Malaysia
$85 \%$ of the total global energy production for stationary power generations and transportations. Coupled with the higher demand for energy growth, it is without a doubt that these nonrenewable resources are continuously depleted at an accelerated rate. The exhaustion of the current fossil fuel reserves is speculated to be within the range of 20 to 1000 years subjected to its geographical reserves [1-4]. According to a statistical report by International Energy Agency [5], global energyrelated carbon dioxide emissions increased by nearly $14 \%$ from the last decade with $33.3 \mathrm{Gt}$ carbon dioxide emissions in 2019. Electricity and heat generation sector continue to be the principal factor to contribute to $41.4 \%$ of the total carbon dioxide emission followed by transportation sector with 24.5\% [6]. The substantial release of carbon dioxide emissions into the atmosphere continues to contribute considerably towards global warming activities and induces progressive climate changes as consequence.

In the Southeast Asian region, neighbouring countries continue to play pivotal roles in bid to curb global warming activities contributed from fossil fuels through valorisation of biomass resources to produce renewable energy. For example, Malaysia had introduced various initiatives, such as National Biofuel Policy 2006, National Biomass Strategy 2020 and 
Renewable Energy Act 2010 [7], despite being one of the largest shareholders of Southeast Asia's fossil fuel resources. Neighbouring countries such as Indonesia had introduced the National Energy Policy (Presidential Regulation No. 5/2006) to reduce fossil-based resources consumption by $83 \%$ while complementing with various renewable energy resources [8]. Thailand had revised the country's Renewable Energy Development Plan Master Plan (REDP: 2008-2022) in 2012 to align the nation towards "Low-Carbon Society" to develop Alternative Energy Development Plan (AEDP: 2012-2021). The revised plan aimed to promote the utilization of renewable energy, constituting largely of bioenergy supply, by $25 \%$ of its total energy consumption by 2021 [9]. Nevertheless, the initiatives formulated were primarily engaged in production of liquid biofuels rather than focusing on gaseous bioenergy such as biohydrogen. The objective of this review paper aims to provide an insight into the latest development of biohydrogen (green hydrogen) production through valorisation of biomass from various hydrogen production pathways (HPPs) in an effort to realise the transition towards a decarbonised hydrogen economy.

Decarbonisation of the energy systems and transportation sectors continues to be challenging [10,11], owing to the current available scale and cost-effective production method of RE resources. In this context, hydrogen, a non-toxic and clean energy carrier, remains as a promising alternative with its high-energy density of $120 \mathrm{MJ} / \mathrm{kg}$ that is approximately 3 times greater than gasoline [12]. In addition, spent hydrogen does not emit anthropogenic gases and can be readily exhausted into water upon conversion to energy. At present, the proposition of a hydrogen economy to replace the current fossil fuel economy for the enhancement of energy system remains highly prospective [13]. Sgobbi et al. [14] had forecasted the role of hydrogen in energy system decarbonisation in Europe between 2030 to 2050 to be very positive growth with relatively small investment costs in infrastructures. Not only that, the Asian region also plays a significant role in the development of hydrogen economy due to the abundant biomass resources available that is viewed as an important commodity for green hydrogen production, while associating itself with strong renewable energy policies in the surrounding Asian countries [15]. Notwithstanding, commodities for industrial applications are likely to be imposed in the initial hydrogen economy exploration, followed by power generation and transportation sectors [16].

While hydrogen itself is a clean fuel, its current production is often accountable for the emission of carbon. "Grey hydrogen" is hydrogen produced from fossil fuel resources such as natural gas and coal to emit by-product carbon dioxide. At present, $96 \%$ of hydrogen is produced through carbon intensive processes, where steam reforming of natural gas accounted to $48 \%$ of total production capacity while petroleum fractionation and coal gasification make up to $30 \%$ and
$18 \%$ production capacity respectively [17]. The remaining $4 \%$ production is mainly made up by electrolysis and other renewable resources. With that being said, the transition from "grey hydrogen" to "green hydrogen" is a potential paradigm shifter in meeting the global energy demands sustainably. The Hydrogen Council had reported that the hydrogen demand for the existing applications alone could extend to 70 million tons which is equivalent to $10 \mathrm{EJ}$ based on the increasing chemicals production [16] However, if the hydrogen is obtained solely from fossil fuel sources, the $\mathrm{CO}_{2}$ emissions to be estimated approximately $500 \mathrm{Mt}$ of $\mathrm{CO}_{2}$ [16]. Decarbonisation of hydrogen production (grey hydrogen) can be carried out by implementing carbon capture and storage (CCS) integration (blue hydrogen) or considering the use of clean energy sources (green hydrogen), which are expected to reduce annual carbon dioxide emissions by nearly 440 million tonnes in 2050 [16]. Figure 1 highlights the various types of hydrogen respective to the HPPs available.

The generation of bioenergy from biomass-based feedstocks have garnered widespread attention in the past decade due to its low-cost and low-carbon emission. In particular, biomass continues to play an important role that acts as a stimulus for economic growth via energy production in least developed to developing status countries $[18,19]$. Biomass presents an inexpensive alternative for hydrogen generation compared to water electrolysis, as the costs of electricity in electrolysis process accounts for $80 \%$ of the production costs of hydrogen [20]. Biomass gasification is found to be the most sustainable pathway apart from other HPPs such as steam methane reforming, wind-based electrolysis and coal gasification [21]. Nevertheless, there are several critical challenges in the production of biohydrogen from biomass feedstocks. Valorisation of biomass wastes via thermochemical conversion routes, such as pyrolysis and gasification processes, often requires high temperature conditions. Furthermore, physicochemical properties and morphological irregularity of various biomass feedstocks are also determining factors in conversion efficiency and products [22]. As such, smaller particle size encourages higher production of hydrogen and carbon monoxide gases, while moisture content do not affect syngas heating value and its composition significantly [23]. These factors often translate differently at pilot scales. For example, higher moisture content requires longer heating duration and this indirectly increases operational costs to obtain similar yield. In addition, the capital costs incurred for preparation of smaller particle feedstock sizes should be justify against the potential additional production yield of hydrogen. Nevertheless, the implementation of the aforementioned HPPs seeks to foresee greater transition towards decarbonisation of energy sector through the share of renewable energy (RE) sources while corresponding to the regressive use of fossil fuel resources. 


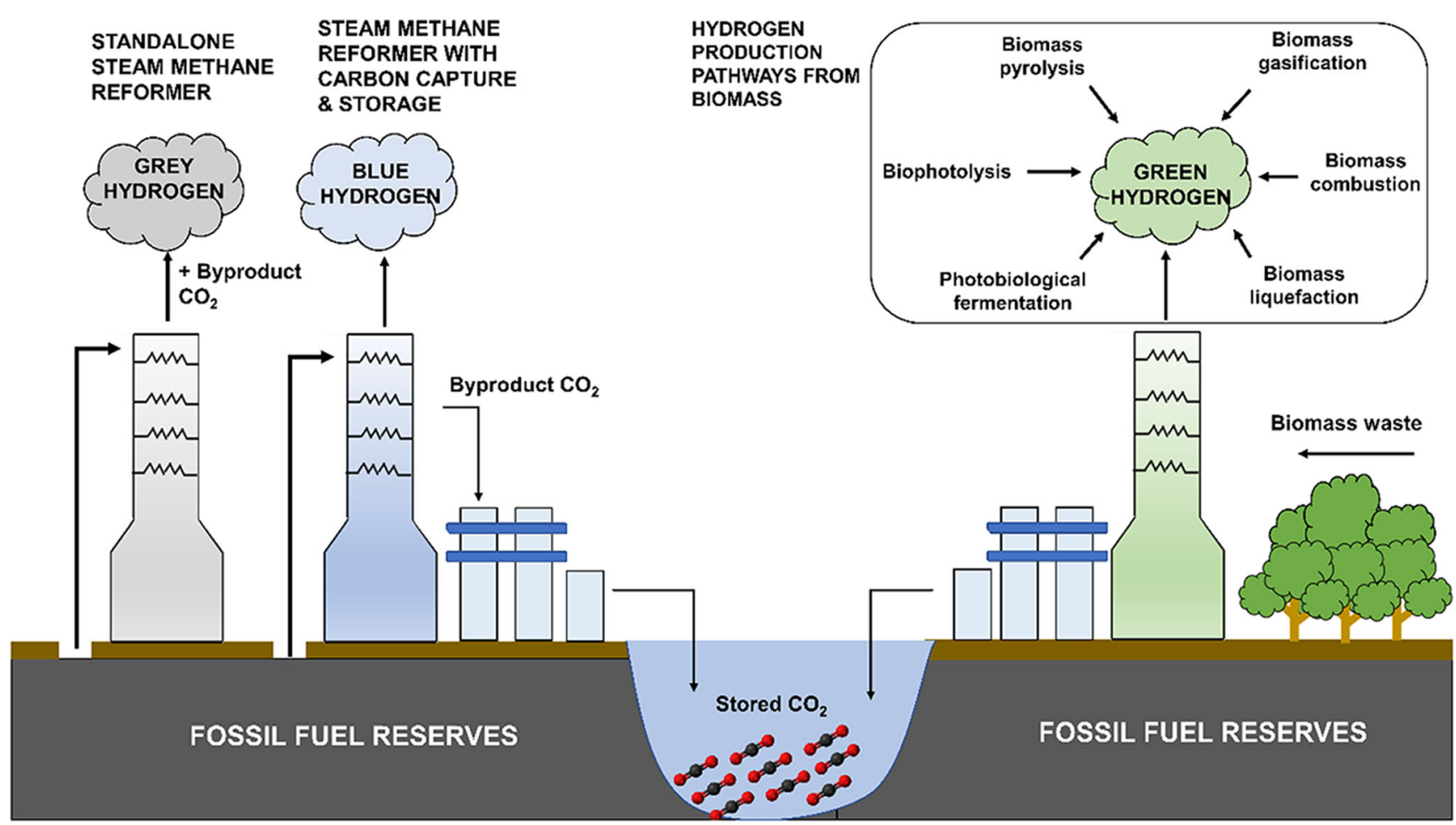

Fig. 1 Graphical representation of different HPPs and the associated produced hydrogen types

In the subsequent sections of this review paper, the authors will review the various HPPs from biomass feedstocks via thermochemical conversion and biochemical pathways. Thermochemical conversion pathways are comprised of pyrolysis, combustion, gasification and liquefaction processes, while direct and indirect bio-photolysis, photobiological fermentation and electrochemistry process are part of biochemical conversion pathways. This review will also discuss on the current constraints in realising the technological potential of green hydrogen production.

\section{Supply, demand, and outlook of biohydrogen}

Presently, power generation from renewables continues to rise uptrend globally to achieve a significant progress in the power sector. The renewable and sustainable sources can be from wind, nuclear, hydropower, biomass, and solar energy. Table 1 highlights the comparative benchmarking between fossil fuel-based and non-fossil fuel-based energy production sources for the production of energy in 2019. Clearly, fossil fuel-based sources such as gas, oil, and coal sources continue to dominate the energy produced with its relative production costs at the expense of high environmental impacts negatively. With that being said, renewable generation capacity source had significantly grew by $7.9 \%$ in 2018 and is foreseen to continue its upward trend in the near future, specifically bioenergy and solar energy in the Asian region [29].
Hydrogen possesses the highest energy density which provides much more benefits compared to any other fuels. It is found that hydrogen produced from fossil fuel results in the formation of carbon dioxide as a source of by-product and attributes to adverse environmental effects. However, hydrogen produced from renewable and sustainable source known as biohydrogen is said to be a clean energy carrier since the combustion process leads to water formation, which creates an attractive energy source compared to other renewable sources [30]. Furthermore, biohydrogen also attributes to positive outcomes in social, environmental, and economic aspects [31]. This indicates that biohydrogen has the potential to decrease the heavy dependency on the conventional fossil fuels and reduce greenhouse gases emissions from both the industrial and transportation sectors [31]. According to Kapdan and Kargi [20], it is reported that biohydrogen provides a higher energy yield $(\sim 118.2 \mathrm{~kJ} / \mathrm{g})$ of 2.75 times compared to hydrocarbon fuels. Figure 2 displays an anticipation of increasing forecast global share of hydrogen consumption together with biofuels, and natural gas to year 2050 [20]. It is observed that hydrogen contributes an incremental of $18 \%$ when compared to the total automotive fuel consumption [32].

Table 2 shows hydrogen production and total primary energy supply (TPES) in three different main groups for trading year of 2040 [33]. The three main groups investigated for hydrogen trading in 2040 by ERIA are classified into exporting, intra-regional, and importing groups. ERIA also addressed the regional energy balance characteristics by dividing two regions for Malaysia and Indonesia. For Malaysia, 
Table 1 Comparative benchmarking between fossil fuel-based and non-fossil fuel-based energy production sources based on generation costs and environmental impacts

\begin{tabular}{|c|c|c|c|c|c|}
\hline \multirow{2}{*}{$\begin{array}{l}\text { Types } \\
\text { Fossil fuel-based }\end{array}$} & \multirow{2}{*}{$\begin{array}{l}\text { Source } \\
\text { Gas }\end{array}$} & \multicolumn{2}{|c|}{ Energy produced in 2019 [24] } & \multirow{3}{*}{$\begin{array}{l}\text { Power generation costs }(\mathrm{USD} / \mathrm{kWh}) \\
0.0098[25] \\
0.041-0.24[26]\end{array}$} & \multirow{2}{*}{$\begin{array}{l}\text { Environmental impacts } \\
\text { High }\end{array}$} \\
\hline & & $39292 \mathrm{TWh}$ & $22.66 \%$ & & \\
\hline & Oil & $53620 \mathrm{TWh}$ & $30.93 \%$ & & \\
\hline & Coal & $43849 \mathrm{TWh}$ & $25.29 \%$ & $0.0069[25]$ & \\
\hline \multirow[t]{7}{*}{ Non fossil fuel-based } & Wind & $3540 \mathrm{TWh}$ & $2.04 \%$ & $0.053-0.115[27]$ & Low \\
\hline & Nuclear & $6923 \mathrm{TWh}$ & $3.99 \%$ & $0.030[28]$ & Moderate \\
\hline & Hydropower & $10455 \mathrm{TWh}$ & $6.03 \%$ & $0.047[27]$ & Moderate \\
\hline & Traditional Biomass & $11111 \mathrm{TWh}$ & $6.40 \%$ & - & - \\
\hline & Solar & $1793 \mathrm{TWh}$ & $1.03 \%$ & $0.068[27]$ & Low \\
\hline & Modern Biofuels & $1143 \mathrm{TWh}$ & $0.65 \%$ & $0.066[27]$ & Moderate \\
\hline & Other renewables & $1614 \mathrm{TWh}$ & $0.93 \%$ & - & - \\
\hline \multicolumn{2}{|c|}{ Total Energy Production in 2019} & $173340 \mathrm{TWh}$ & $100 \%$ & & \\
\hline
\end{tabular}

"Peninsula Malaysia" and "Borneo" are defined as the "moredemand-intensive region" and "more supply-intensive region" respectively [33]. Meanwhile, "Eastern regions" (Kalimantan, Natuna, Maluku, Papua, and Sulawesi) and both Java and Sumatra are classified into "more demand-intensive region" and "demand-supply balanced" region respectively for Indonesia.

From the Economic Research Institute for ASEAN and East Asia (ERIA) analysis in 2019, it is anticipated that both the demand and supply of hydrogen in the East Asia Summit (EAS) to be well-proportioned between these three main groups by the year of 2040 [33]. However, there are certain countries which will rely very much on demand growth hence this will result to hydrogen imports to take place. Nevertheless, production of main hydrogen from conventional fossil fuels is predicted to shift towards renewable sources, such as solar, biomass, wind, hydro, and geothermal, from year 2020 onwards attributed to the current technological development pace [33]. The supply potential from renewable and sustainable hydrogen source will also increase with the advancement of technology for the respective hydrogen production method which also includes water electrolysis and also carbon capture, utilisation, and storage (CCUS) [33].

The evaluation of the economical aspect for hydrogen production also plays a crucial factor other than analysing the supply and demand aspect of hydrogen production. Currently, the production of hydrogen from steam-reforming process is reported to be USD 18/ million BTU, which is said to be three times higher than the cost of natural gas ( USD 6/million BTU) [34]. Meanwhile, the production of hydrogen from electrolysis is $\sim$ USD 28/million BTU [34]. Hence, the aspect to highlight the necessity to develop the wastebased hydrogen economy to meet the ever-rising energy demand while fostering energy security in a sustainable manner is essential. Besides that, comparative studies on energy efficiency and economic analysis for hydrogen production from renewable source and fossil fuels are
Fig. 2 Forecast global share of biofuels, natural gas, and hydrogen contributions for automotive fuel supply. Data adapted and modified from [20]

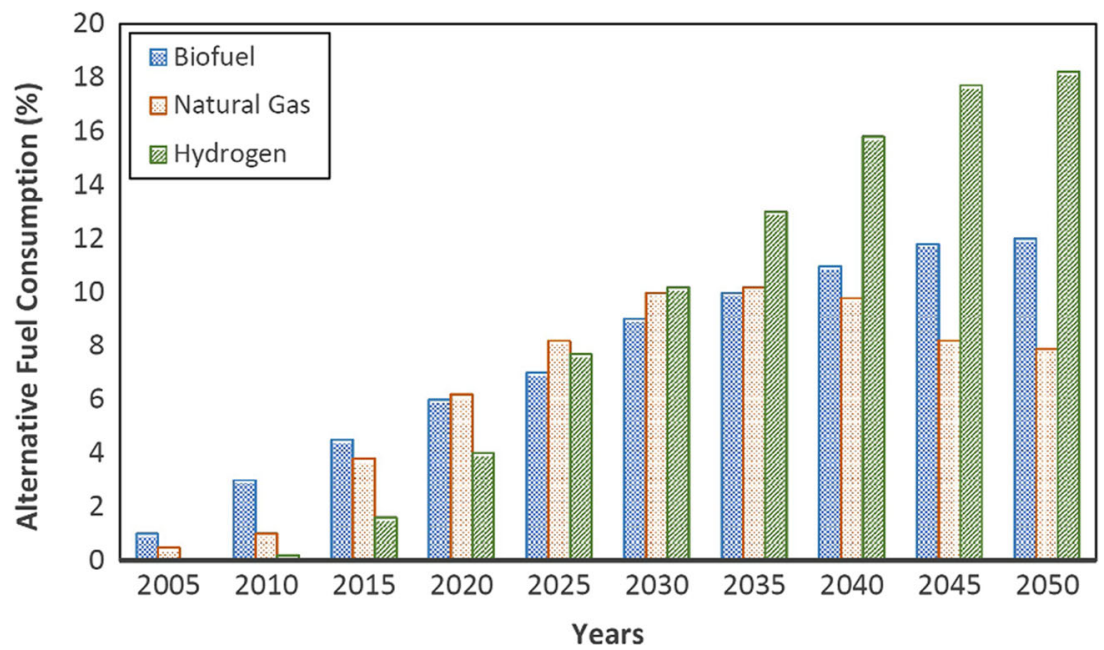


Table 2 Hydrogen production and total primary energy supply (TPES) in 2040 in three different main groups (exporting, intra-regional, and importing) [33]

\begin{tabular}{|c|c|c|c|c|c|c|c|}
\hline \multirow[t]{2}{*}{ Group } & \multirow[t]{2}{*}{ Country } & \multicolumn{3}{|c|}{$\begin{array}{l}\text { Hydrogen TPES } \\
\text { (mtoe/year) }\end{array}$} & \multicolumn{2}{|c|}{ Hydrogen production (mtoe/year) } & \multirow[t]{2}{*}{$\begin{array}{l}\text { Different } \\
\text { (F-S3) }\end{array}$} \\
\hline & & Scenario 1a & Scenario $2 \mathrm{a}$ & Scenario 3a & Forecast & Potential & \\
\hline \multirow[t]{6}{*}{ Exporting } & Australia & 1.5 & 3.5 & 5.7 & 13.7 & 823.2 & 8.0 \\
\hline & Indonesia (Eastern) & 0.9 & 2.0 & 3.3 & 10.1 & 121.2 & 6.8 \\
\hline & Malaysia (Borneo) & 0.3 & 0.7 & 1.2 & 6.2 & 26.0 & 5.0 \\
\hline & Brunei Darussalam & 0.1 & 0.1 & 0.2 & 1.3 & 2.9 & 1.1 \\
\hline & New Zealand & 0.1 & 0.3 & 0.5 & 1.1 & 7.9 & 0.6 \\
\hline & Lao PDR & 0.0 & 0.0 & 0.1 & 0.1 & 0.1 & 0.0 \\
\hline \multirow[t]{8}{*}{ Intra-regional } & China & 11.8 & 27.7 & 45.5 & 45.5 & 124.0 & 0.0 \\
\hline & India & 13.4 & 29.3 & 46.5 & 46.5 & 597.5 & 0.0 \\
\hline & Indonesia (Java, Sumatra) & 3.5 & 8.0 & 13.3 & 13.3 & 26.5 & 0.0 \\
\hline & Vietnam & 2.0 & 4.3 & 6.8 & 6.8 & 29.5 & 0.0 \\
\hline & Thailand & 0.7 & 1.5 & 2.4 & 2.4 & 42.2 & 0.0 \\
\hline & Philippines & 0.6 & 1.3 & 2.1 & 2.1 & 40.4 & 0.0 \\
\hline & Myanmar & 0.3 & 0.8 & 1.4 & 1.4 & 26.9 & 0.0 \\
\hline & Cambodia & 0.1 & 0.2 & 0.4 & 0.4 & 1.6 & 0.0 \\
\hline \multirow[t]{4}{*}{ Importing } & Japan & 3.7 & 8.4 & 13.3 & 0.1 & 0.1 & -13.1 \\
\hline & Republic of Korea & 2.7 & 5.8 & 8.9 & 0.3 & 0.3 & -8.7 \\
\hline & Malaysia (Peninsula) & 1.2 & 2.9 & 4.8 & 2.1 & 5.7 & -2.7 \\
\hline & Singapore & 0.2 & 0.5 & 0.7 & 0.0 & 0.0 & -0.7 \\
\hline Total & & 43.4 & 97.3 & 157.1 & 153.6 & $1,876.0$ & -3.6 \\
\hline
\end{tabular}

${ }^{\text {a }}$ Scenario 1 - costs include the large-scale hydrogen production and carrier synthesis usage, coastal vessel transport of $600 \mathrm{~km}$, truck transport of 100 $\mathrm{km}$, and hydrogen refuelling stations. Scenario 2 - costs include the large-scale hydrogen production and carrier synthesis usage, train transport of 300 $\mathrm{km}$, truck transport of $100 \mathrm{~km}$, and hydrogen refuelling station. Scenario 3-costs include the large-scale hydrogen production and carrier synthesis usage, truck transport of $100 \mathrm{~km}$ and hydrogen refuelling stations

needed to assess the feasibility for the technological process implementation [35]. Hosseini et al. [30] evaluated both overall efficiency and hydrogen prices on the various thermochemical processes. Among the thermochemical processes investigated, hydrogen produced from steam methane reforming produced the highest overall efficiency of $65-75 \%$ with a hydrogen cost of USD 5-8/GJ [35]. Furthermore, it is found that hydrogen produced from steam methane reforming process is three times lower than that for hydrogen produced from direct gasification of biomass [35]. So far, there are no detailed analysis on the socio-economic analysis for both biochemical and thermochemical conversion on biohydrogen production. Hence, the limitations of the technological aspects during the biohydrogen production process and economic barriers for both biochemical and thermochemical conversion need to be addressed in order to move towards commercialisation status for biohydrogen production. To do so, the establishment of systematic supply chain management system to optimise and integrate biomass and waste resources for biohydrogen production needs to be implemented.
Additionally, a joint effort among nations could realise this strategic goal.

\section{Biohydrogen production pathways (B-HPPs)}

The methods for biohydrogen production can essentially be compartmentalised into two main categories: namely thermochemical conversion route and biochemical conversion route. The former relies on the use of high temperature operations to degrade biomass wastes to produce biohydrogen where the types and conditions of feedstocks used can heavily influence the outcome of the products. Biochemical conversion route emphasises more on the physical conditions of the medium (living organisms) and types of catalysts used. To date, typical downstream processing methods for separation of $\mathrm{H}_{2}$ from other process by-products are absorption, adsorption, membrane separation, and cryogenics separation, irrespective of upstream processing routes (thermochemical or biochemical $\mathrm{H}_{2}$ production) [36]. Nevertheless, both production pathways offer a more sustainable approach for production of hydrogen compared to the current conventional route. 


\subsection{Thermochemical conversion route}

Waste decomposition for biohydrogen generation from industrial and agricultural waste including landfills' wastes, plastic, and biomass can be achieved by thermo-conversion process such as pyrolysis, combustion, gasification and liquefaction. These processes require different process conditions to yield different range of products in the form of liquid, solid and gas. Figure 3 summarised the overall differences in conditions and products of the thermochemical processes, respectively. For instance, pyrolysis and gasification are typical conversion process to obtain gaseous and liquid products from biomass or coal by combining Fischer-Tropsch and other synthesis process. Heat and steam are conventional products from direct combustion that can be used in gas turbines for power generation, or pyrolysis and gasification which is the pathways in hydrogen production. Hydrogen is one of the gaseous products in which its quality is dependent on the raw material composition, water content, temperature, heating rate, type of gasifier, and oxidation of pyrolysis products [38].

Production of hydrogen from biomass can be achieved by several processes and conversion stages. There are several methods and technologies applicable for hydrogen production such as electrolysis, biomass hydrogen and solar conversion [22]. Electrolysis produces hydrogen by water-splitting using electrical energy from any renewable resources. Meanwhile biomass hydrogen can be generated either by thermochemical or biochemical conversion process. Furthermore, hydrogen production through solar conversion can be done by using thermal decomposition from solar generated heat or photolysis of an electrochemical systems [22].

This paper focuses on hydrogen production through thermo-chemical conversion processes which include combustion, pyrolysis, liquefaction and gasification. Thermoconversion of biomass may experience different stages according to difference process conditions influenced by temperature and pressure. Drying is the initial stage of thermal conversion of a biomass while gasification is the last stage of thermal conversion technology. However, production of hydrogen from biomass through gasification involved all these conversion stages [22]. The selection of thermochemical conversion pathway ultimately dependent on the required output from the selected process either to generate heat, power or electricity through solid, liquid or gaseous products. Then, the suitable technology can be further evaluated based on the required technology, technology maturity and operating condition such as atmosphere and temperature of the conversion pathways. The selection of technology will further influence the operation cost and efficiency of the conversion pathways. Summary of technical properties for each conversion pathways is described in Table 3 below.

\subsubsection{Pyrolysis}

Pyrolysis is recognised as a thermal degradation process of a solid material such as biomass, in the absence of oxidizing agent and produced solid in a form of char, liquid in a form of oil and gaseous product [41]. It is regarded as one of the greener processes that contribute towards greater carbon savings, minimizing landfills utilisation and better waste management for industries. For instance, Britain has established a consortium named Carbon Trust to pioneer the development of technology that convert municipal and wood waste to transport biofuel including enhancement on pyrolysis process [38]. Notwithstanding, pyrolysis biofuel has the potential to reduce carbon footprint by $95 \%$ compared to fossil fuels [38]

Pyrolysis is mostly defined into three types, namely conventional or slow pyrolysis, fast pyrolysis, and flash pyrolysis, which differs according to its operating temperature, heating rate and residence time to affect the range of product yield [42]. Details about pyrolysis operating condition that can influence product yields are summarised in Table 4. Pyrolysis of

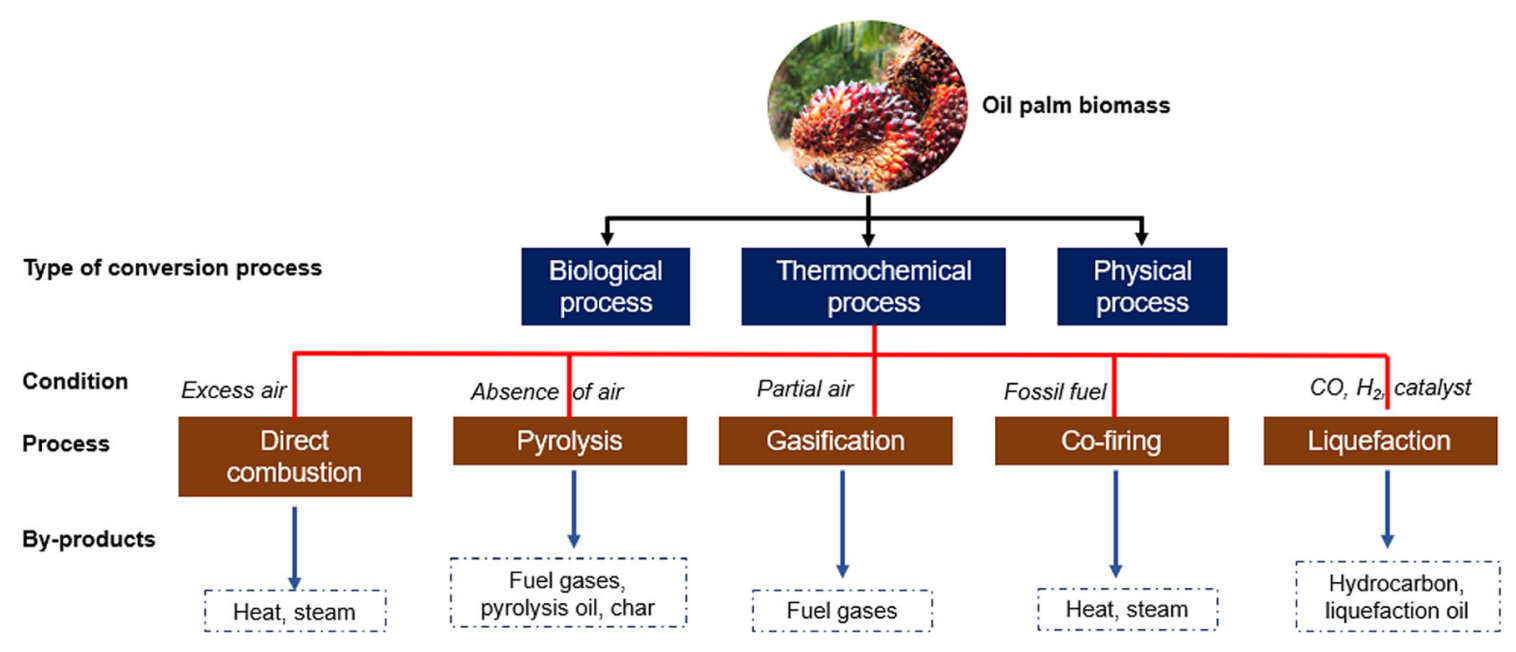

Fig. 3 Description of overall conversion technology of biomass to biofuel. Modified and sketched from [37] 
Table 3 Summary of technical properties of thermochemical pathways [39, 40]

\begin{tabular}{|c|c|c|c|c|c|}
\hline Conversion pathway & Atmosphere & Temperature & Technology & Product & Output \\
\hline Combustion & $\begin{array}{l}\text { - Air } \\
\text { - Combustible gases }\end{array}$ & $700-1000^{\circ} \mathrm{C}$ & $\begin{array}{l}\text { Incinerator, } \\
\text { Fixed bed } \\
\text { Fluidised bed }\end{array}$ & Solid and gaseous product & $\begin{array}{l}\text { - Heat \& power } \\
\text { - Electricity }\end{array}$ \\
\hline $\begin{array}{l}\text { Hydrothermal } \\
\text { liquefaction }\end{array}$ & $\begin{array}{l}\text { - Water } \\
\text { - Acidic/base } \\
\text { - Ionic liquid }\end{array}$ & $180-250^{\circ} \mathrm{C}$ & $\begin{array}{l}\text { Reaction vessel } \\
\text { Pressure reactor }\end{array}$ & Liquid (> 60\%) and solid product & - Liquid fuel \\
\hline Pyrolysis & $\begin{array}{l}\text { - Air } \\
\text { - Inert }\end{array}$ & $300-500^{\circ} \mathrm{C}$ & Fixed bed & $\begin{array}{l}\text { Liquid (more than } 50 \% \text { ), solid, } \\
\text { and gaseous product }\end{array}$ & $\begin{array}{l}\text { - Liquid, solid \& gaseous fuel } \\
\text { - Electricity }\end{array}$ \\
\hline Gasification & $\begin{array}{l}\text { - Inert (nitrogen) } \\
\text { - Steam } \\
\text { - Air/Oxygen }\end{array}$ & Higher than $500^{\circ} \mathrm{C}$ & Fluidised bed & $\begin{array}{l}\text { Gaseous (more than } 80 \% \text { ) } \\
\text { and solid product }\end{array}$ & $\begin{array}{l}\cdot \text { Heat \& power } \\
\text { - Hydrogen } \\
\text { - Electricity }\end{array}$ \\
\hline
\end{tabular}

biomass yield released a mixture of gaseous compounds such as hydrogen, carbon monoxide and carbon dioxide as well as volatile compound, char and moisture, where the general chemical reactions are described in Eq. 1 to Eq. 3 below [43]. Slow pyrolysis is able to produce bio-gas about 10$35 \%$ while the potentially higher syngas yield can be obtained through flash pyrolysis at high temperatures [42]. Normally, flash pyrolysis is performed at temperatures higher than 650 ${ }^{\circ} \mathrm{C}$ with contact times of less than one second to favour approximately $80 \%$ production efficiency of the gaseous product [44].

$$
\begin{aligned}
& \text { Biomass }+ \text { Heat } \rightarrow \mathrm{H}_{2}+\mathrm{CO}+\mathrm{CO}_{2}+\mathrm{CH}_{4} \\
& + \text { Gaseous hydrocarbons }
\end{aligned}
$$

Gasification process:

$$
\text { Biomass } \rightarrow \mathrm{H}_{2}+\mathrm{CO}+\mathrm{CO}_{2}+\mathrm{N}_{2}
$$

Steam reforming:

Biomass $\rightarrow \mathrm{H}_{2}+\mathrm{CO}+\mathrm{CO}_{2}$

Fast or flash pyrolysis followed by steam reforming is seen as typical pathways to obtain hydrogen from biomass feedstock. Arregi et al. [45] used continuous fast pyrolysis method to pyrolysis pine wood sawdust at $500{ }^{\circ} \mathrm{C}$ in a conical spouted bed reactor (CSBR). The pyrolysis vapour was directed to inline steam reforming using fluidised bed reactor with $\mathrm{Ni}$ commercial catalyst to obtain higher yield compared to other alternatives, such as direct steam gasification or bio-oil reforming. This method observed maximum hydrogen yield of $117 \mathrm{~g} / \mathrm{kg}$ of biomass which was obtained at $600{ }^{\circ} \mathrm{C}$ using steam to biomass ratio of 4. Parthasarathy and Narayanan [46] performed a life-cycle analysis on biomass-to-oil (BTO) process produced using fast ablative pyrolysis method using feedstock of wood chips from forest residues. Assessment of BTO-CHP-system in all environmental impact indicated lower environmental impact values compared to standard diesel oil fuelled combined heat power (CHP) plant. For the impact categories of acidification potential (AP), photochemical ozone creation potential (POCP) and ozone depletion potential (ODP), BTO-CHP-system obtained 244\%, 263.2\%, and $292.4 \%$ respectively, which were considerably lower compared to CHP plant [46]. Jaffar et al. [41] performed pyrolysis of waste sawdust for synthetic gas production including biohydrogen, using various types of metal-based catalysts to optimise the hydrogenation process. Hydrocarbon volatiles and gases from pyrolysis undergo catalytic cracking, gasification reactions and steam reforming. The gaseous products were condensed to a mixture of water and bio-oil traces prior

\begin{tabular}{|c|c|c|c|c|c|c|}
\hline \multirow[t]{2}{*}{ Type } & \multicolumn{3}{|l|}{ Condition } & \multicolumn{3}{|c|}{ Product yield (wt\%) } \\
\hline & Temperature $\left({ }^{\circ} \mathrm{C}\right)$ & Pressure & Others & Liquid & Gas & Solid \\
\hline Fast pyrolysis & $400-550$ & Atmospheric & $\begin{array}{l}\text { Short residence time }(0.5-2 \mathrm{~s}) \\
\text { Absence of oxygen }\end{array}$ & $67-75$ & $13-25$ & $12-19$ \\
\hline Slow pyrolysis & $300-750$ & Atmospheric & $\begin{array}{l}\text { Low heating rate } \\
\text { Long residence time } \\
\text { Absence of oxygen }\end{array}$ & $30-50$ & $15-30$ & $30-60$ \\
\hline Flash pyrolysis & $400-1000$ & Atmospheric & Rapid heating rate $(<0.5 \mathrm{~s})$ & $60-70$ & $10-15$ & $15-25$ \\
\hline
\end{tabular}
to catalytic hydrogenation process. Using pyrolysis

Table 4 Classification of pyrolysis according to operating conditions and effects on range of product yield [39] 
temperature of $800^{\circ} \mathrm{C}$, the hydrogen yield varies from 33 to 72 vol\% when steam reforming took place between 600 to $900{ }^{\circ} \mathrm{C}[41]$.

Hydrogen via pyrolysis and continued with gasification process can also be obtained using waste plastics or polypropylene. A screw kiln continuous reaction system consisted of two-stages reactor was developed with first stage was pyrolysis of the plastic followed by catalytic gasification of the product pyrolysis gases in the second stage [47]. The system produced maximum hydrogen of $0.22 \mathrm{~g} \mathrm{H}_{2} / \mathrm{g}$ polypropylene, which was $52 \%$ of the maximum theoretical hydrogen available in the polypropylene at gasification temperature of $800{ }^{\circ} \mathrm{C}$ and Ni-Mg-Al catalyst. Similarly, Duman and Yanik [48] also explored hydrogen production in two stages fixed bed reactor system through steam pyrolysis of olive pomace using catalyst from char. The system involved a semi-batch reactor for pyrolysis and a continuous fixed-bed catalytic reactor. Pyrolysis was initiated when the catalytic reactor temperature reached desired temperature to minimise the condensation of product gas to achieve hydrogen yield of $315.3 \mathrm{~mL} / \mathrm{g}$. Ni-based brown coal char also exhibited promising catalyst to produce high amount of hydrogen.

Pyrolysis has significant effects on quality of gaseous products during gasification process. Prasertcharoensuk et al. [49] studied the behaviour of pyrolysis in gasification of high volatile content lignocellulosic materials affecting the properties of volatiles and char that are feedstock for the gasification step. The study found hydrogen increased by $18 \mathrm{~mol} \%$ and aromatic compounds decreased up to $50.6 \%$ when pyrolysis temperatures was higher than $800{ }^{\circ} \mathrm{C}$ and steam to carbon biomass ratio was 5.7. The overall composition of product gases during gasification process at $1000{ }^{\circ} \mathrm{C}$ indicated higher hydrogen content due to higher pyrolysis temperature applied. The optimization of pyrolysis condition for maximizing hydrogen production can be performed by using modelling and software. For instance, Hossain et al. [50] optimised pyrolysis of oil palm fibre (OPF) for hydrogen and biochar production using microwave by applying quadratic model developed by response surface methodology (RSM) based on central composite design (CCD). The optimised parameters were $700{ }^{\circ} \mathrm{C}, 508.36 \mathrm{~W}$ and $1200 \mathrm{~cm}^{3} / \mathrm{min} \mathrm{N}_{2}$ to obtain maximised hydrogen production of $9.74 \mathrm{~g} / \mathrm{kg}$ with a desirability value of 0.992 .

\subsubsection{Combustion}

Biomass combustion is the simplest thermo-chemical conversion technology that takes place in the presence of air that produces heat and power, which consists of consecutive heterogeneous and homogeneous reactions [39]. It is composed of exothermic chemical reactions that releases chemical energy to be converted into mechanical and electrical energy [51]. Eq. 4 summarised the process equation.

Biomass + Oxygen $\rightarrow$ Carbon Dioxide + Water + Heat

Combustion can be another conversion pathways for biomass or waste materials to generate hydrogen as the secondary energy sources in form of heat or electricity [52]. A typical biomass combustion applied in the industry generates heat and steam for power generation. Combustion via incineration has been widely used in waste management since it is able to reduce the volume and weight of waste up to $90 \%$ and $70 \%$, respectively. Thus combustion is able to reduce the demand for landfill while demonstrating higher efficiencies of energy recovery compared to anaerobic digestion [53]. However, the quality of biomass combustion and amount of generated heat varied according to particle size and properties of the feedstock, temperature, and combustion atmosphere. Biomass combustion produced an average thermal energy of $20 \mathrm{MJ} /$ $\mathrm{kg}$ of biomass [54] and it is environmentally challenging due to high emissions of NOx, carbon dioxide, and particulate matter as well as ash handling [55]. Burned biomass formed residues as ash and residual carbon that varies in content according to efficiency and condition of combustion chamber [56]. Biomass combustion are divided into four stages, where moisture loss is initiated in the first stage. This is followed by combustion of light volatiles compounds within temperature range of 203 to $396^{\circ} \mathrm{C}$ followed by higher volatile compounds typically within 320 to $438^{\circ} \mathrm{C}$ prior to final stage to observe char combustion [57]. Combustion is carried out inside combustion chambers between 800 to $1000{ }^{\circ} \mathrm{C}$ that favours dry biomass feedstocks with typical moisture content less than $50 \%$ [44].

\subsubsection{Gasification}

Gasification converts a solid or liquid feedstock into its gaseous components known as synthesis gas or syngas, which are mainly hydrogen and carbon monoxide that primarily formed at high gasification temperatures such as above $1200^{\circ} \mathrm{C}$ [55]. Gasification is endothermic reaction and yet it can be designed to thermally balance as exothermic and endothermic reactions [58]. In 2010, worldwide biomass gasification is composed of $0.5 \%$ while coal, petroleum, natural gas, and pet-coke remained as the dominant feedstock [58]. Table 5 summarises the type of feedstock that is commonly used in countries that are dominant in gasification technology. The USA showed the most variation of feedstock used while Japan leads in biomass, wood, municipal waste, and sludge utilisation.

Anniwaer et al. [60] synthesised hydrogen-rich gas from bio-chars that was synthesised using marine biomass eelgrass through steam gasification. The bio-chars were initially 
Table 5 Type of feedstocks utilised by countries through dominant involvement in gasification technology [59]

\begin{tabular}{|c|c|c|c|c|c|c|c|c|c|}
\hline Feedstock & China & Japan & USA & Finland & Sweden & Greece & Turkey & Spain & India \\
\hline Biomass & $x$ & $x$ & $x$ & & & & & & \\
\hline Wood & & $x$ & $x$ & & & & & & \\
\hline Peat & & & $x$ & $\times$ & & & & & \\
\hline Black liquor & & & $x$ & $x$ & $x$ & & & & \\
\hline Municipal waste & & $\times$ & $x$ & & & & & & \\
\hline Agricultural & & & $x$ & & & $\times$ & $x$ & $\times$ & \\
\hline Sludge & & $x$ & $x$ & & & & & & \\
\hline Rice husk & $x$ & & & & & & & & $x$ \\
\hline
\end{tabular}

derived by pyrolysis process at $550^{\circ} \mathrm{C}$ to produce the largest amount of hydrogen yield at the gasification temperature of $850^{\circ} \mathrm{C}$ in the presence of steam. Enhancement in hydrogen production, reaction rates, and sharp decreased in carbon dioxide content were observed when eelgrass biochar were mixed with calcined seashells. Interestingly, the steam gasification system can be innovated to minimise tar formation to enhance the hydrogen production. For instance, Xiao et al. [61] proposed decoupled dual loop gasification system (DDLG) to enhance hydrogen-rich gas production in steam gasification of biomass. The system involved pyrolysis and gasification, tar cracking and reforming and char combustion which were decoupled into fuel reactor, reformer and combustor to observe hydrogen concentration of 40.8 vol\% with tar content as low as $14.1 \mathrm{~g} / \mathrm{Nm}^{3}$.

Biomass gasification involves several processes or stages and reactions which occur simultaneously [58] as following:

- Drying or dehydration - free water in the feedstock evaporates, leaving dry material. It is a relatively fast process and occurs up to $120^{\circ} \mathrm{C}$.

- De-volatization or pyrolysis_-breaking of the weaker chemical bonds compound in the feedstock which release volatile gases such as tar vapours, methane, and hydrogen. High molecular weight char is formed and underwent gasification reactions at the later stage. Primary oxygenated liquids are formed and volatiles are produced until temperature reached approximately $350-400^{\circ} \mathrm{C}$ [62]. The pyrolysis stage is endothermic and occurs within 250 and $700^{\circ} \mathrm{C}[44]$

- Oxidation or gasification - The remaining char reacts with carbon dioxide and steam, leading to the formation of the final syngas such as carbon monoxide and hydrogen. Oxygen, steam, and carbon dioxide are typical oxidiser for the gasification process. Tars and gaseous hydrocarbons formed at pyrolysis stage are mostly converted into fuel gases during the secondary reactions that require combustion and reforming process. Bourdard reaction, character reform, water gas displacement, and methanation are among other reaction that may take place at this stage [44].

The typical reaction for hydrogen production through gasification reaction of biomass can be represented as follows [58]:

a) Gasification reaction

$$
\begin{aligned}
& \mathrm{C}+\mathrm{CO}_{2} \leftrightarrow 2 \mathrm{CO} \Delta \mathrm{H}=172 \mathrm{~kJ} / \mathrm{mol} \\
& \mathrm{C}+\mathrm{H}_{2} \mathrm{O} \leftrightarrow \mathrm{CO}+\mathrm{H}_{2} \quad \Delta \mathrm{H}=131 \mathrm{~kJ} / \mathrm{mol} \\
& \mathrm{C}+2 \mathrm{H}_{2} \mathrm{O} \rightarrow \mathrm{CO}_{2}+2 \mathrm{H}_{2} \quad \Delta \mathrm{H}=190 \mathrm{~kJ} / \mathrm{mol} \\
& \mathrm{C}+\mathrm{O}_{2} \rightarrow \mathrm{CO}_{2} \quad \Delta \mathrm{H}=-393 \mathrm{~kJ} / \mathrm{mol}
\end{aligned}
$$

b) Partial oxidation reaction

$$
\begin{aligned}
& \mathrm{C}+1 / 2 \mathrm{O}_{2} \rightarrow \mathrm{CO} \quad \Delta H=-110 \mathrm{~kJ} / \mathrm{mol} \\
& \mathrm{CO}+1 / 2 \mathrm{O}_{2} \rightarrow \mathrm{CO}_{2} \quad \Delta H=-283 \mathrm{~kJ} / \mathrm{mol} \\
& \mathrm{CH}_{4}+1 / 2 \mathrm{O}_{2} \rightarrow \mathrm{CO}+\mathrm{H}_{2} \quad \Delta H=-36 \mathrm{~kJ} / \mathrm{mol} \\
& \mathrm{H}_{2}+1 / 2 \mathrm{O}_{2} \rightarrow \mathrm{H}_{2} \mathrm{O} \quad \Delta \mathrm{H}=-242 \mathrm{~kJ} / \mathrm{mol}
\end{aligned}
$$

c) Water gas shift reaction

$$
\mathrm{CO}+\mathrm{H}_{2} \mathrm{O} \leftrightarrow \mathrm{CO}_{2}+\mathrm{H}_{2} \quad \Delta \mathrm{H}=-41 \mathrm{~kJ} / \mathrm{mol}
$$

Table 6 described the different types of gasifier designs. Gasification in fixed bed is normally applied at lower air velocity, in contrary to fluidised bed which uses air oxygen or steam as the oxidizing agent that flows at higher velocity. Entrained flow gasification involved formation of small droplets or particles from feedstock into oxidizing agent such as oxygen or steam. Such flow is usually referred as suspension flow or dust cloud gasifiers and is mainly applied for large scale using coal or petroleum based feedstock [64]. Biomass gasification is considered immature technology for wide market application as its design are varied and dominant design is yet established [64]. 
Table 6 Design of gasifier and operating condition for different type of gasifier [63]

\begin{tabular}{|c|c|c|c|c|c|c|}
\hline \multirow{2}{*}{$\begin{array}{l}\text { Gasifier } \\
\text { type } \\
\text { Gasifier } \\
\text { design }\end{array}$} & \multicolumn{2}{|c|}{ Fixed bed } & \multicolumn{2}{|l|}{ Fluidised bed } & \multicolumn{2}{|c|}{ Entrained flow } \\
\hline & Updraft & Downdraft & $\begin{array}{l}\text { Bubbling } \\
\text { fluidised bed }\end{array}$ & $\begin{array}{l}\text { Circulating } \\
\text { fluidised bed }\end{array}$ & $\begin{array}{l}\text { Entrained } \\
\text { flow-down }\end{array}$ & $\begin{array}{l}\text { Entrained } \\
\text { flow-up flow }\end{array}$ \\
\hline Temperature & \multicolumn{2}{|c|}{$300-1000^{\circ} \mathrm{C}$, } & $650-950{ }^{\circ} \mathrm{C}$ & $800-1000^{\circ} \mathrm{C}$ & $>1200^{\circ} \mathrm{C}$ & $1050-1400^{\circ} \mathrm{C}$ \\
\hline Pressure & \multicolumn{2}{|c|}{ Atmospheric } & $1-35$ bar & 1-19 bar & $20-50 \mathrm{bar}$ & 27.5 bar \\
\hline
\end{tabular}

\subsubsection{Hydrothermal liquefaction}

Biomass conversion into useful products including hydrogen can also be performed through hydrothermal liquefaction. The process eliminates the necessity of dry feedstock which is suitable for biomass feedstock with high-moisture content, where hydrothermal liquefaction can be performed in either subcritical or supercritical water mediums [65]. Hydrothermal liquefaction demonstrates high gasification efficiency and hydrogen selectivity, which accelerates the formation of clean gaseous products and minimises formation of tars and chars [66]. The critical temperature $\left(\mathrm{T}_{\mathrm{c}}\right)$ and pressure $\left(\mathrm{P}_{\mathrm{c}}\right)$ for water is $374^{\circ} \mathrm{C}$ and $22.1 \mathrm{MPa}$ respectively that operates similarly to catalytic gasification and high temperature gasification processes. Amendment to temperature and pressure beyond the critical point promotes transition of liquid-like densities towards gas-like densities of supercritical water without changing the phase [67].

Hydrothermal liquefaction process is initiated at $100^{\circ} \mathrm{C}$ by dispersion of water-soluble parts in biomass into water to subsequently hydrolyse at temperature above $150^{\circ} \mathrm{C}$. The cellulosic and hemicellulosic components within biomass consequently disintegrate into its monomeric chains to form a slurry once temperature reaches $200^{\circ} \mathrm{C}$ under $1 \mathrm{MPa}$ [68]. Water can act as an acid or base catalyst at subcritical and near-critical regions the ionic reaction mechanism is favoured owing to the higher concentrations of hydronium $\left(\mathrm{H}_{3} \mathrm{O}^{+}\right)$and hydroxide $\left(\mathrm{OH}^{-}\right)$ions. These ions may cause severe corrosion at high concentration and it is more dominant in subcritical region since the solvation ability in supercritical region is lesser [67]. Water act as a reactant in hydrolysis reaction through following mechanism:

$$
\mathrm{A}-\mathrm{B}(\text { Reactant })+\mathrm{H}-\mathrm{OH}(\text { Water }) \rightarrow \mathrm{A}-\mathrm{H}+\mathrm{B}-\mathrm{OH}
$$

Overall, process of hydrothermal liquefaction involved three steps, namely depolymerization of biomass, decomposition of biomass monomers and re-condensation of reactive intermediates [69]. The final product of hydrothermal liquefaction is in liquid form which typically referred as bio-oil or bio-crude. The obtained bio-oil undergo subsequent reforming to obtain the hydrogen via syngas produced [70]. Bio-oil reforming has lower operating temperature and can be translated into lower energy inputs when compared to direct gasification method. In general, bio-oil separation and reforming are necessary after hydrothermal liquefaction of biomass, followed by syngas cleaning and water-gas shift reaction, and finally hydrogen purification to obtain biohydrogen [70].

Kipcak and Akgun [66] studied supercritical water gasification (SCWG) of biomass as a novel approach for hydrogen production. Organic material demonstrates high solubility in supercritical water which enable the process to perform in single homogenous phase without mass transfer limitations [66]. Thus, hydrogen production by SCWG reforming various hydrocarbons offers many benefits such as feedstock flexibility, fast reaction, compact reactor system, high conversions, and low carbon monoxide contents. However, SCWG method requires further consideration to overcome critical challenges such as accurate process condition, system configuration, biomass complexity, and catalyst material, prior established to commercialization stage [67]. Okolie et al. [71] reviewed process parameters, reaction mechanisms for SCWG and found recyclability of homogeneous catalyst questionable especially for low-temperature catalytic SCWG. Nevertheless, integration of Fischer-Tropsch into SCWG process can accelerate a practical implementation of SCWG process for hydrogen production. Details on type of reactor used in hydrothermal liquefaction are further described in Table 7.

\subsubsection{Limitation of thermochemical conversion}

The market of gasification using waste materials including biomass currently remain to depend on niche application and government support as such the technology are well locally demonstrated [64]. However, gasification using waste materials and biomass are currently considered more matured compared to other thermochemical conversion pathways. Nevertheless, the limitation of thermochemical conversion is also dependent on the quality of the process. For instance, the quality of combustion conversion technology highly dependent on the burnout quality of the process which is associated to sufficient mixing of combustible gases and air, residence time and temperature [54]. The employment of combustion process can also be limited by the deposition of undesired ash and coke formation in the incinerator due to required high temperature condition. 
Table 7 Type of reactors used for hydrogen production through liquefaction of different type of feedstock [71]

\begin{tabular}{lllll}
\hline Reactor & Batch reactor & Diamond anvil cell & Continuous reactor & Fluidised bed reactor \\
\hline Biomass type & Cellulose \& lignin & Cellulose & Clover grass \& corn silage & Chicken manure \\
Temperature $\left({ }^{\circ} \mathrm{C}\right)$ & 400 & 350 & 700 & 600 \\
Pressure $(\mathrm{MPa})$ & 25 & 16.5 & 45 & 24 \\
Other condition & Reaction time: $20 \mathrm{~min}$ & Heating rate: & Reaction time: $16.82 \mathrm{~min}$ & \\
Catalyst & Nickel & $2.2 \mathrm{C} / \mathrm{s}$ & $\mathrm{KHCO}_{3}$ & Activated carbon \\
Max. $\mathrm{H}_{2}$ Yield & $1.23 \mathrm{mmol} / \mathrm{g}$ - cellulose & $74 \%$ with $40 \mathrm{wt} \%$ Nickel & $29.7 \%$ & $25.2 \mathrm{~mol} / \mathrm{kg}$ with $9 \mathrm{wt} \% \mathrm{AC}$ \\
& $2.52 \mathrm{mmol} / \mathrm{g}$ - lignin & & & \\
\hline
\end{tabular}

Hydrothermal liquefaction is considered to have a complex reaction mechanism when biomass is used as the fuel feedstock. The exact mechanism pathways remain unclear and the possibility of intermediate reaction "seemingly-infinite" [72]. Depolymerisation of biomass that has complex compound and components of lignocellulosic material further increased the complexity of the reaction pathways. In addition, the feedstock will require certain limit of particle size to ensure fit to reactor and efficient liquefaction process. Besides, alkaline treatment and contaminant removal are also crucial for the process to ease and stabilise slurry pumping [72].

Liquefaction is considered as a less attractive process when comparing to pyrolysis process. Liquefaction product which is bio-oil typically illustrated lower yield, require catalyst for performance enhancement and high water content, which is not favourable condition for fuel application [73]. Besides, bio-oil from liquefaction process also have the risks of low calorific value, viscous and corrosive [48].

Finally, challenges of flash pyrolysis process mostly associated to the properties of yield bio-oil such as poor thermal stability, corrosive, solid contaminants, viscosity increase over time and formation and pyrolytic water. Slow pyrolysis process also has its own limitation. Besides requiring additional energy consumption, long residence time and low heat transfer also potential to crack the primary product hence affecting the quality of bio-oil [42]. The challenges and limitations of thermochemical conversion pathways demand further research and innovative development for advancement at larger scale.

\subsection{Biochemical pathways}

In relative to thermochemical means, biochemical pathways furnish a more promising cum sustainable $\mathrm{H}_{2}$ synthesis route from wastes by virtue of its low energy necessity (low process temperature) and trivial gaseous pollutant $\left(\mathrm{NO}_{\mathrm{x}}\right.$ and $\left.\mathrm{SO}_{\mathrm{x}}\right)$ emission $[74,75]$. Howbeit, the usage of microbes as biocatalysts in the biochemical $\mathrm{H}_{2}$ production has several inevitable obstacles, viz. sluggish bioprocess, stringent growth condition, concomitant by-product formation, and low $\mathrm{H}_{2}$ yield. Until today, biochemical $\mathrm{H}_{2}$ synthesis did not successfully commercialised yet despite it received a lot of scientific attention about four decades ago. To address its current limitations, it is worthy to discuss various $\mathrm{H}_{2}$-producing biochemical routes from wastes, viz. (i) biophotolysis of water (direct or indirect biophotolysis) [76, 77], (ii) anaerobic fermentation of organics (dark fermentation and photofermentation) [78, 79], and (iii) microbial electrolysis of organics [80, 81]. To ease the technology screening, the process aspects of different biochemical $\mathrm{H}_{2}$ production routes are compiled in Table 8 for a quick evaluation of process maturity. Table 8 clearly narrates that (i) direct and indirect biophotolysis have low process maturity, (ii) photofermentation and microbial electrolysis exhibit moderate process maturity, and (iii) dark fermentation possess high process maturity. Henceforth, the following subsections briefly described the pros, cons, mechanisms, and performance of each biochemical pathway in deriving $\mathrm{H}_{2}$ from wastes.

\subsubsection{Bio-photolysis of water}

Biophotolysis of water received scientific attention for its $\mathrm{H}_{2}$ production about 45 years ago. Biophotolysis of water is a photobiological water splitting process which facilitated by oxygenic $\left(\mathrm{O}_{2}\right.$-producing) photosynthetic (light-utilizing for $\mathrm{CO}_{2}$ fixation) microbes, primarily cyanobacteria and microalgae with the aid of light-harvesting complex chlorophylls [36, 82]. In fact, $\mathrm{H}_{2}$ formation from water biophotolysis (Eq. 15) only requires water and artificial/solar light (photon energy, $\mathrm{h} v$ ); however, oxygenic photosynthetic microbes need $\mathrm{CO}_{2}$ (for $\mathrm{CO}_{2}$ fixation) and nutrients (i.e., carbon, nitrogen, and mineral sources) to ensure proper metabolism and growth [76, 77, 83, 84]. Despite possible harness of solar light, the artificial lights that primarily radiate visible light such as cool white fluorescent light [83-87], halogen light [88, 89], and Xenon light [83] are preferred to maximise light absorption of cyanobacteria and algae, thereby to ascertain maximal $\mathrm{H}_{2}$ yield. Additionally, $\mathrm{CO}_{2}$ is supplied by shaking $[86,88,90$, 


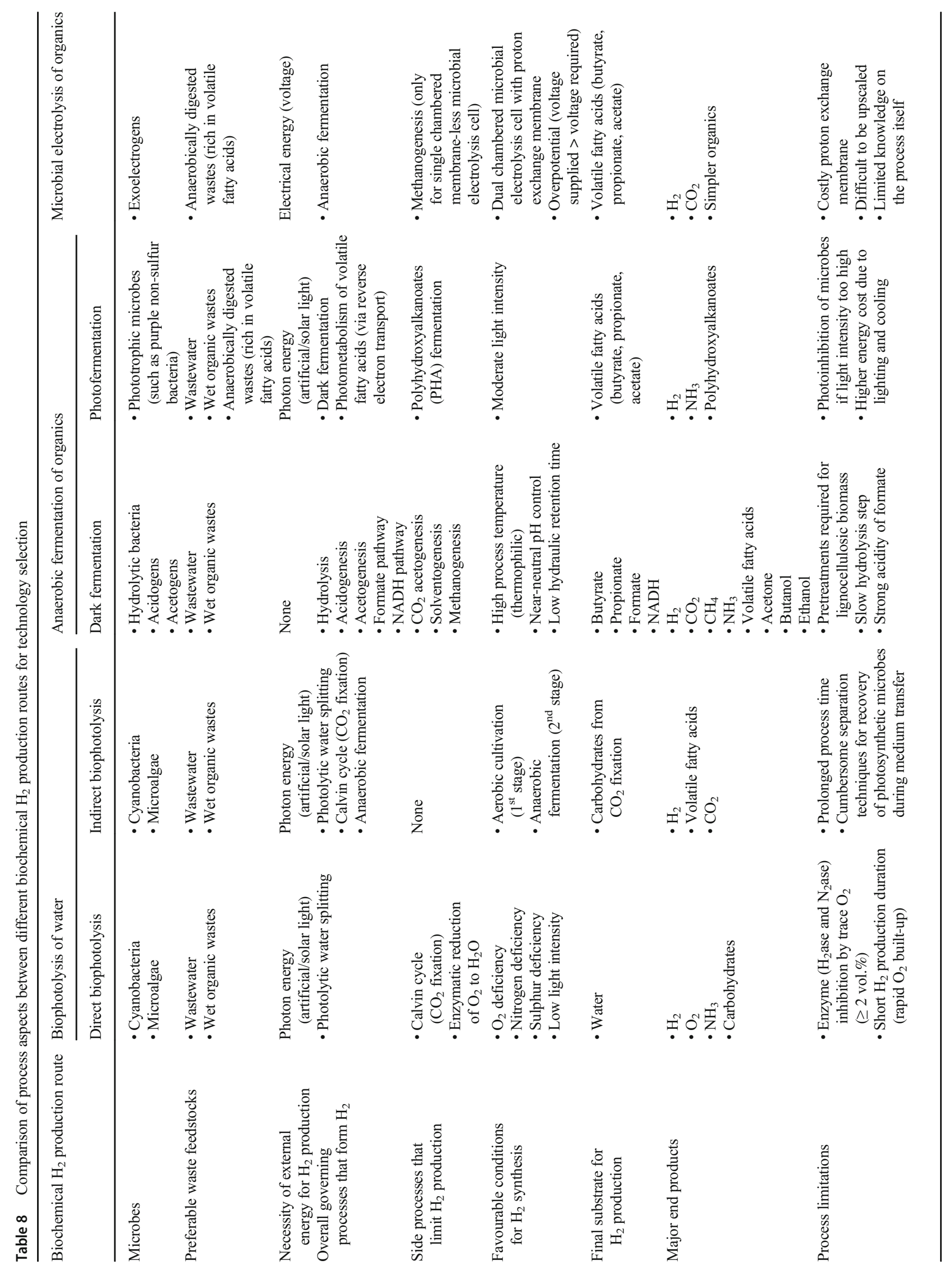




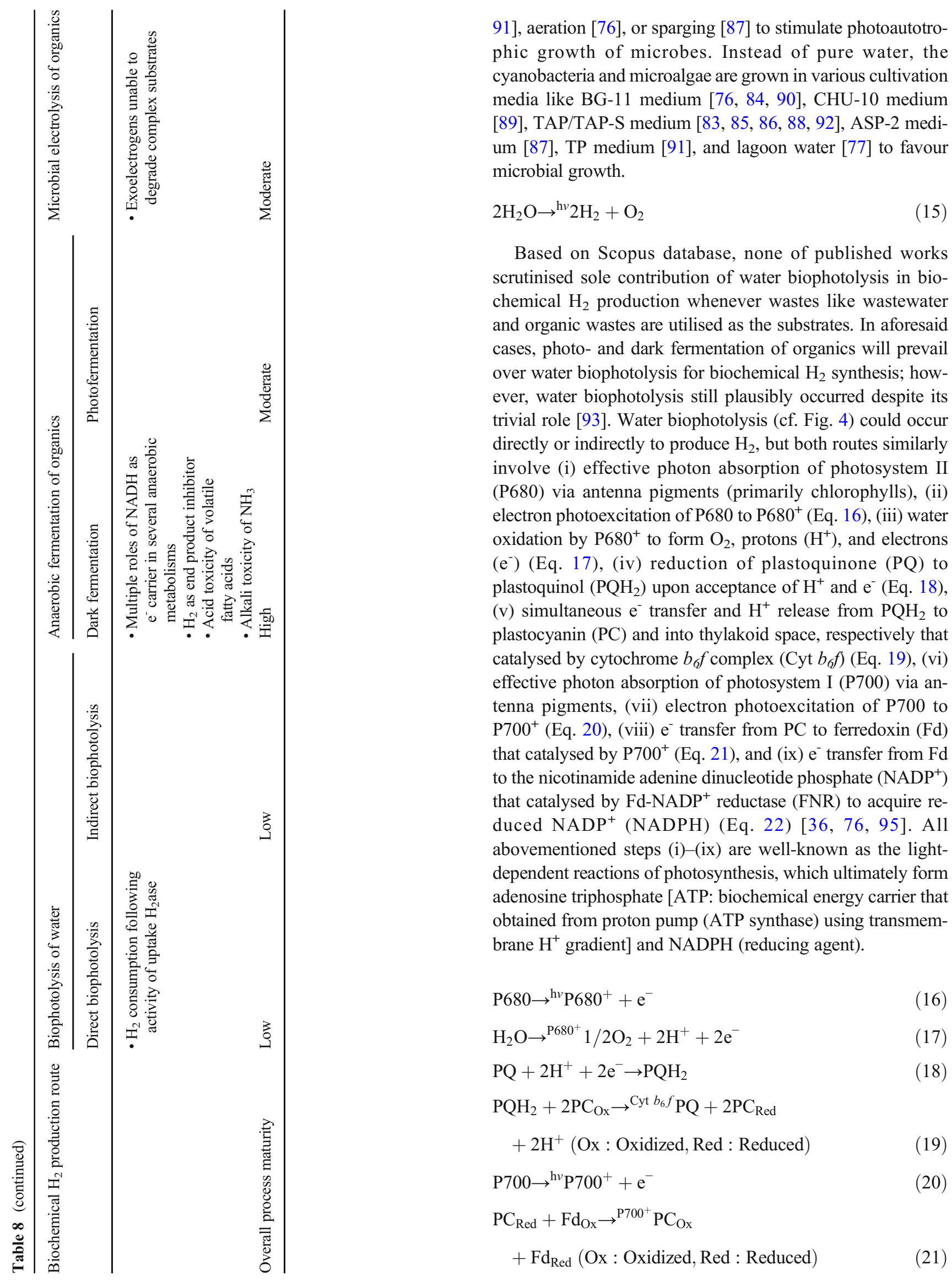


$2 \mathrm{Fd}_{\text {Red }}+\mathrm{NADP}^{+}+\mathrm{H}^{+} \rightarrow{ }^{\mathrm{FNR}^{2}} 2 \mathrm{Fd}_{\mathrm{Ox}}$

+ NADPH (Ox : Oxidized, Red : Reduced)

Direct biophotolysis generates $\mathrm{H}_{2}$ from water splitting through light-dependent reactions of photosynthesis [36]. Direct biophotolysis ideally offers direct conversion of solar energy to $\mathrm{H}_{2}$ energy with the aid of hydrogenase $\left(\mathrm{H}_{2}\right.$ ase; found in cyanobacteria and microalgae) and nitrogenase $\left(\mathrm{N}_{2}\right.$ ase; found in some cyanobacteria) $[36,95]$. Withal, photosynthetic microbes preferably utilise ATP and NADPH for the light-independent reaction of photosynthesis $\left(\mathrm{CO}_{2}\right.$ fixation or Calvin cycle) to synthesise metabolizable complex organics as food rather than the $\mathrm{H}^{+}$-utilizing enzymatic pathways to form $\mathrm{H}_{2}[76,96]$. During direct biophotolysis, enzymatic $\mathrm{H}_{2}$ production via $\mathrm{H}_{2}$ ase or $\mathrm{N}_{2}$ ase respectively expends NADPH and ATP; hence, photosynthetic microbes only favour enzymatic $\mathrm{H}_{2}$ synthesis via $\mathrm{H}_{2}$ ase $\left(\mathrm{O}_{2}\right.$ deficiency) or $\mathrm{N}_{2}$ ase $(\mathrm{N}$ deficiency) under specific circumstances to attain aerobic respiration (aerobic metabolism of organics using $\mathrm{O}_{2}$ ) or microbial growth (protein synthesis from $\mathrm{N}$ compounds), separately $[76,95]$. Under $\mathrm{O}_{2}$ deficiency, $\mathrm{Fd}$ or NADPH individually transfers their $\mathrm{e}^{-}$to $\mathrm{H}^{+}$for $\mathrm{H}_{2}$ production via $\mathrm{Fd} \mathrm{H}_{2}$ ase (Eq. 23) or $\mathrm{NADP}^{+} \mathrm{H}_{2}$ ase (Eq. 24), thereby stimulates the water oxidation (Eq. 16) for $\mathrm{O}_{2}$ evolution with a lower $\mathrm{H}^{+}$concentration [76]. When $N$ is deficient, photosynthetic microbes are forced to perform ATP-intensive $\mathrm{N}_{2}$ fixation (Eq. 25), where Fd transfers $\mathrm{e}^{-}$to $\mathrm{N}_{2}$ and $\mathrm{H}^{+}$for the production of $\mathrm{NH}_{3}$ (preferred substrate of amino acid synthesis) with concomitant formation of $\mathrm{H}_{2}$ as by-product [95].

$$
\begin{aligned}
& 2 \mathrm{Fd}_{\mathrm{Red}}+2 \mathrm{H}^{+} \rightarrow{ }^{\mathrm{Fd} \mathrm{H}_{2} \text { ase }} 2 \mathrm{Fd}_{\mathrm{Ox}} \\
& +\mathrm{H}_{2} \text { (Ox : Oxidized, Red : Reduced) } \\
& \mathrm{NADPH}+\mathrm{H}^{+} \rightarrow \mathrm{NADP}^{+} \mathrm{H}_{2} \text { ase } \mathrm{NADP}^{+}+\mathrm{H}_{2} \\
& \mathrm{~N}_{2}+8 \mathrm{H}^{+}+8 \mathrm{e}^{-}+16 \mathrm{ATP} \rightarrow{ }^{\mathrm{N}_{2} \text { ase }} 2 \mathrm{NH}_{3}+\mathrm{H}_{2} \\
& +16 \mathrm{ADP}+16 \mathrm{P}_{\mathrm{i}}
\end{aligned}
$$

Main limitations of direct biophotolysis are enzyme $\left(\mathrm{H}_{2}\right.$ ase and $\mathrm{N}_{2}$ ase) inhibition by trace $\mathrm{O}_{2}(\geq 2$ vol.\%) [95, 97], short $\mathrm{H}_{2}$ bioproduction duration (rapid $\mathrm{O}_{2}$ built-up) [93], and $\mathrm{H}_{2}$ consumption following activity of uptake $\mathrm{H}_{2}$ ase [36, 98]. Besides $\mathrm{CO}_{2}$ fixation and $\mathrm{H}_{2}$ production (Eq. 24), NADPH from light-dependent reactions is also utilised to avert photooxidative damage by reducing $\mathrm{O}_{2}$ to water via sequential enzymatic reactions of NADPH dehydrogenase (NDH; Eq. 26) and cytochrome bd quinol oxidase (Cyd; Eq. 27) [76, 99]. Indeed, the $\mathrm{O}_{2}$ represents the inhibitor of direct biophotolysis that restricts the potentiality of $\mathrm{H}_{2}$ bioproduction; hence, effective elimination of $\mathrm{O}_{2}$ during direct biophotolysis is desirable. However, many attempts such as inert gas sparging, $\mathrm{O}_{2}$ scavenging, photosystem II inhibitions, and genetic alteration for faster aerobic respiration are either non-economically viable, imposing irreversible damage, or even counterproductive $\mathrm{H}_{2}$ bioproduction [36, 93]. Lately, the combination of

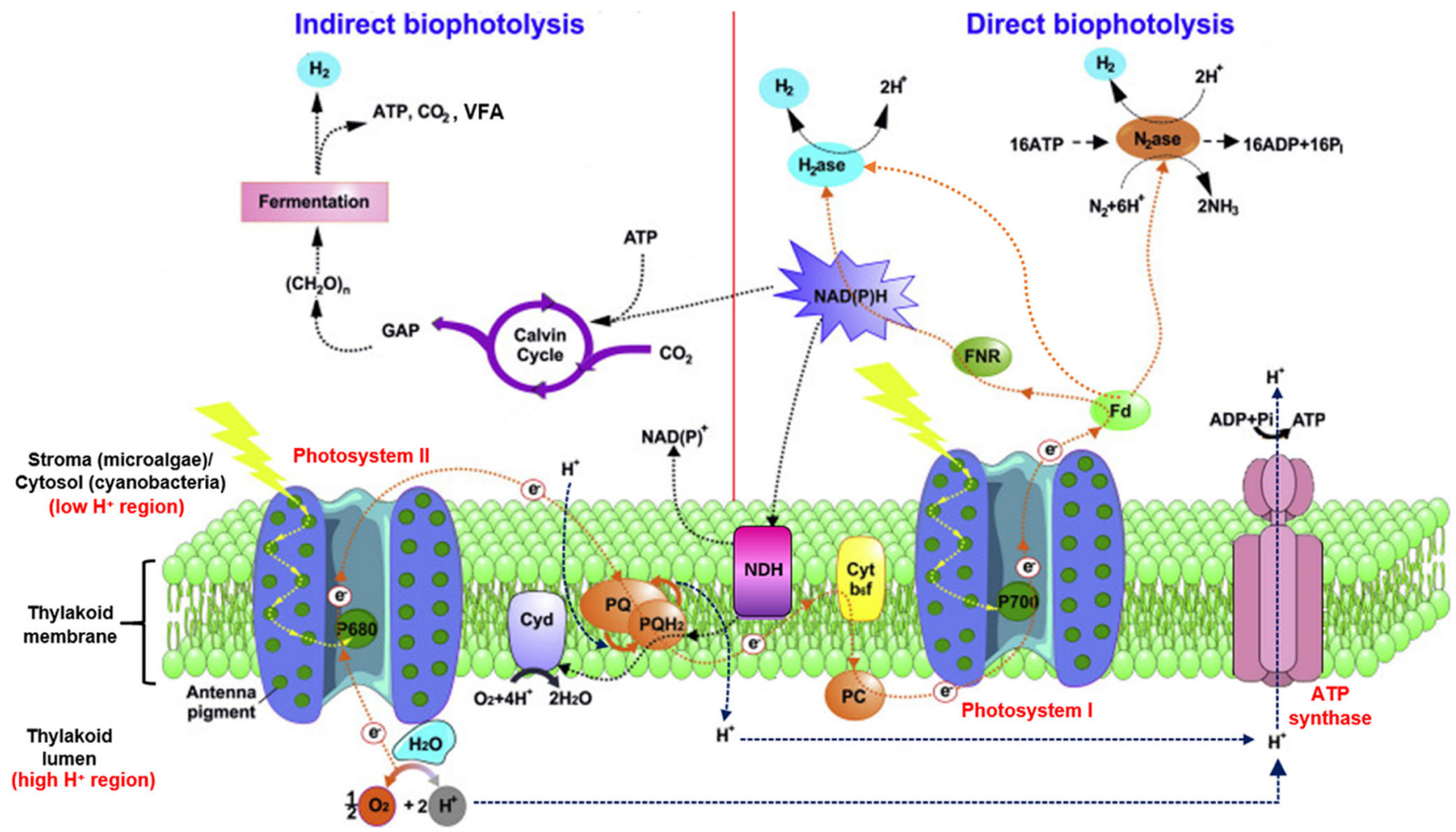

Fig. 4 Mechanism of water bio-photolysis in cyanobacteria and microalgae (adapted from [94]) 
sulphur-deprived medium and low light intensity was found to enhance $\mathrm{H}_{2}$ production from direct biophotolysis as the former reduces $\mathrm{O}_{2}$ formation by impairing maintenance of photodamaged photosystem II's D1 protein while the latter minimises photooxidative damage of D1 protein [100]. Apart from that, some filamentous cyanobacteria able to develop thick-walled heterocyst that shields $\mathrm{N}_{2}$ ase from $\mathrm{O}_{2}$, which is advantageous for $\mathrm{H}_{2}$ production via nitrogen fixation $[36,95]$; nevertheless, heterocyst development is also ATPintensive [76].

$$
\begin{aligned}
& \mathrm{NADPH} \rightarrow{ }^{\mathrm{NDH}} \mathrm{NADP}^{+}+\mathrm{H}^{+} \\
& 1 / 2 \mathrm{O}_{2}+2 \mathrm{H}^{+}+2 \mathrm{e}^{-} \rightarrow{ }^{\mathrm{Cyd}} \mathrm{H}_{2} \mathrm{O}
\end{aligned}
$$

Unlike direct biophotolysis that forms $\mathrm{H}_{2}$ from water splitting, indirect biophotolysis also entails sequential event of (i) Calvin cycle (light-independent reactions of photosynthesis) and (ii) fermentation to indirectly harness the $\mathrm{H}_{2}[36,95,98]$. During Calvin cycle, both NADPH and ATP that generable from light-dependent reactions of photosynthesis are consumed to fix $\mathrm{CO}_{2}$ into the glyceraldehyde 3-phosphate (GAP), viz. the common precursor of complex carbohydrates $\left[\left(\mathrm{CH}_{2} \mathrm{O}\right)_{n}\right][76]$. Through anaerobic fermentation (cf. Section 3.2.2), the metabolizable carbohydrates are biodegraded into volatile fatty acids (VFA), $\mathrm{H}_{2}$, and $\mathrm{CO}_{2}$ for ATP synthesis. Hence, the indirect biophotolysis consists of two distinct stages, $s c$. aerobic cultivation of phototrophic microbes (with $\mathrm{O}_{2}$ liberation) and anaerobic fermentation of endogenous substrates; additionally, the sulfur-deprived medium is used especially for photofermentation to reduce likelihood of photosynthetic $\mathrm{O}_{2}$ evolution $[36,95,100]$. However, the practicability of indirect biophotolysis is questionable with the prolonged process time and cumbersome separation techniques (centrifugation, filtration, etc.) for the recovery of photosynthetic microbes during medium transfer, which may provoke a negative energy ratio due to trivial $\mathrm{H}_{2}$ formation $(56.4$ $\mathrm{mL} / \mathrm{L}$ medium) [100]. Despite cell immobilization technology ease separation, recent study validated cell immobilization on most supports has adverse effect on $\mathrm{H}_{2}$ synthesis via indirect biophotolysis, plausibly due to mass transfer or photon absorption limitations [90].

\subsubsection{Anaerobic fermentation of organics}

Among various biochemical pathways, anaerobic fermentation of organics is the oldest technology studied for $\mathrm{H}_{2}$ formation since 1942. Depending on the necessity of light, anaerobic fermentation is broadly classified into dark fermentation (without light) and photofermentation (with light). For $\mathrm{H}_{2}$ production, the dark fermentation of organics involves catabolism (breakdown of complex molecules), reductive pathway (acceptance of $\mathrm{e}^{-}$), and $\mathrm{H}_{2}$ ase as main enzyme whereas the photofermentation of organic acids entails anabolism (synthesis of large molecules), oxidative pathway (donate of $\mathrm{e}^{-}$), and $\mathrm{N}_{2}$ ase as main enzyme $[96,101,102]$. The inhibitory products for the anaerobic $\mathrm{H}_{2}$ production include volatile fatty acids (acid toxicity from degradation of carbonaceous compounds), ammonia (alkali toxicity from degradation of nitrogenous compounds), and $\mathrm{H}_{2}$ (end product inhibition) [103]. Basically, dark fermentation (Fig. 5(a)) resembles anaerobic degradation that without methanogenesis, composing of three main stages, specifically (i) hydrolysis, (ii) acidogenesis, and (iii) acetogenesis, wherein a group of anaerobic microbes (hydrolytic bacteria, acidogens, and acetogens) responsible for anaerobic biodegradation of organics [109].

During hydrolysis, hydrolytic bacteria decompose the major biopolymers of biomass, viz. carbohydrates, proteins, and lipids in the presence of water to produce respective products like sugars, amino acids, or fatty acids and glycerol via carbohydrolysis (Eq. 28), proteolysis (Eq. 29), and lipolysis (Eq. 30), individually [110]. The ease of hydrolysis of major biopolymers could be ranked as carbohydrates $>$ proteins $>$ lipids [103]. Apart from starches, most carbohydrates of plants exist as dietary fibres, which comprised of three lignocellulosic components known as hemicellulose, cellulose, and lignin with increasing bio-recalcitrance [111]. Effective biodegradation of dietary fibres requires collective groups of diverse enzymes, sc. cellulase for cellulose, hemicellulase for hemicellulose, and ligninolytic enzymes for lignin [112]. Various pretreatment methods (i.e., mechanical, chemical, hydrothermal, thermal, or electromagnetic) are purposed to enhance the susceptibility of lignocelluloses towards biodegradation by weakening interlinkages of lignocellulosic components [113]; howbeit, pretreatments incur additional cost and energy for $\mathrm{H}_{2}$ production. By experimental validation, hydrolysis is proven to be the rate-limiting step of anaerobic $\mathrm{H}_{2}$ production via dark fermentation [114].

Carbohydrates $+\mathrm{H}_{2} \mathrm{O} \rightarrow$ Sugars

Proteins $+\mathrm{H}_{2} \mathrm{O} \rightarrow$ Amino acids

Lipids $+\mathrm{H}_{2} \mathrm{O} \rightarrow$ Fatty acids + Glycerol

When acidogenesis, acidogens degrade the carboncontaining monomers (sugars, amino acids, fatty acids, and glycerol) to myriad organic acids, primarily volatile fatty acids (VFA: acetate, propionate, and butyrate), with a minority of pyruvate, lactase, formate, and some citric acid cycle (CAC) intermediates (i.e., oxaloacetate, malate, fumarate, and succinate) $[109,115]$. Acidogenesis is a complex network of catabolic biochemical reactions, namely (i) glycolysis (for glucose \& glycerol), (ii) fructolysis (for fructose; fructose pathwayglycolysis), (iii) galactolysis (for galactose; galactose pathway-glycolysis), (iv) pentose phosphate pathway-glycolysis (for pentose sugars like xylose \& arabinose), (v) transamination/deamination (for amino acids), (vi) $\beta$ - 


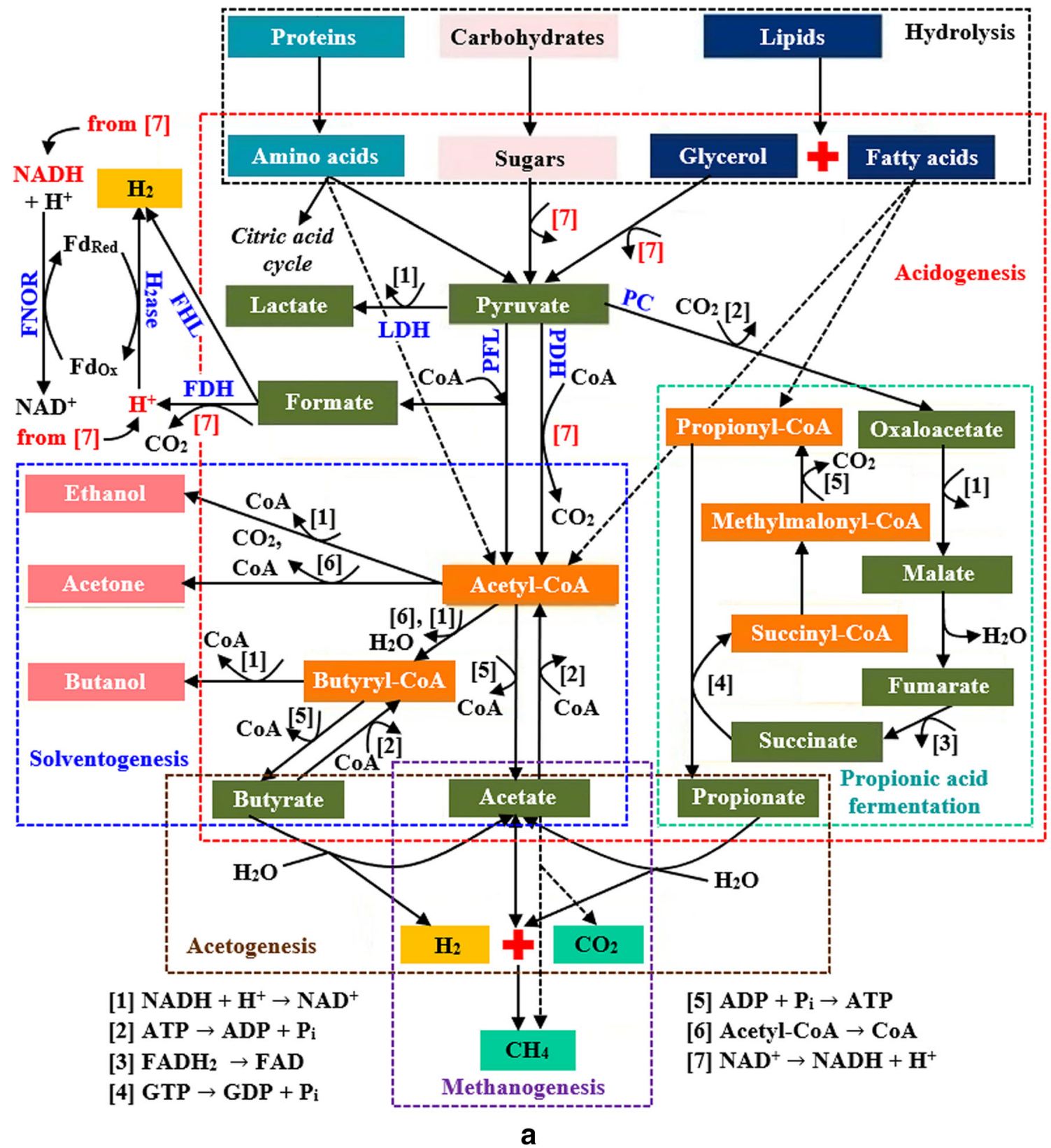

Fig. 5 Mechanism of anaerobic fermentation for hydrogen production: a dark fermentation of organics in anaerobic microbes (adapted from [2]) and $\mathbf{b}$ photo fermentation of organic acids in purple non-sulfur bacteria (sketched based on [104-108])

oxidation (for fatty acids), and (vii) mixed acid fermentation. As shown in Eq. 31, pathways (i)-(iv) mutually degrade all monosaccharides to pyruvate as well as produce NADH and $\mathrm{H}^{+}$via glycolysis [116, 117]. By transamination/deamination, glucogenic amino acids are degraded to CAC intermediates (pyruvate, $\alpha$-ketoglutarate, succinyl-CoA, fumarate, and oxaloacetate) via Eq. 32 whereas ketogenic amino acids are degraded to acetyl-CoA via Eq. 33 [118]. Through $\beta$-oxidation, odd-chain fatty acids are degraded to propionyl-CoA and acetyl-CoA (Eq. 34) while even-chain fatty acids are degraded to acetyl-CoA (Eq. 35) [117]. Meanwhile, glycerol can enter the glycolysis after being converted to dihydroxyacetone phosphate [119]. Under anaerobic condition, pyruvate is enzymatically converted into (i) lactate, (ii) acetyl-CoA, (iii) acetyl-CoA and formate, or (iv) oxaloacetate through lactate dehydrogenase (LDH), pyruvate dehydrogenase (PDH), pyruvate formate lyase (PFL), or pyruvate carboxylase (PC), separately [109]. Besides lactate and formate, mixed acid fermentation also forms (i) acetate and butyrate from acetyl-CoA and (ii) propionate from oxaloacetate (via reverse CAC) [109, 120].

Monosaccharides $\rightarrow$ Pyruvate $+\mathrm{NADH}+\mathrm{H}^{+}$

Glucogenic amino acids $\rightarrow$ CAC intermediates 


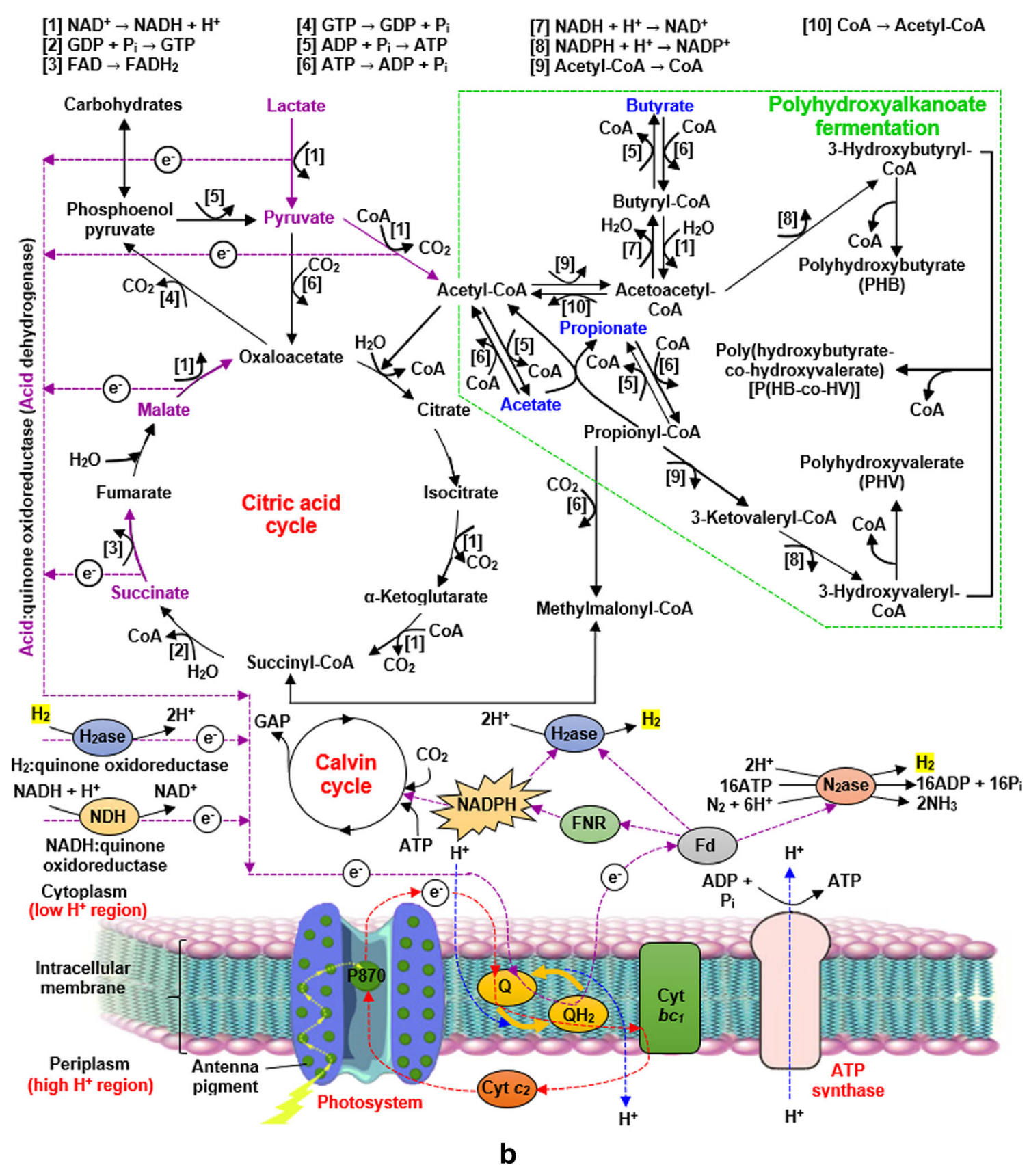

Fig. 5 (continued)

Ketogenic amino acids $\rightarrow$ Acetyl $-\mathrm{CoA}$

Odd-chain fatty acids $\rightarrow$ Propionyl-CoA + Acetyl-CoA

Even-chain fatty acids $\rightarrow$ Acetyl-CoA

During acetogenesis, acetogens form $\mathrm{H}_{2}$ while degrading both propionate (Eq. 36) and butyrate (Eq. 37) to acetate with and without $\mathrm{CO}_{2}$ evolution, respectively. Nevertheless, the $\mathrm{H}_{2}$ could be used up by (i) reversible $\mathrm{CO}_{2}$ acetogenesis (Eq. 38) [110], (ii) solventogenesis of Clostridium sp. (bioconversion of acetate and butyrate to $\mathrm{ABE}$ (acetone, butanol, \& ethanol) solvents to avert VFA toxicity) $[121,122]$, and (iii) methanogenesis (final stage and slowest step of anaerobic degradation) that almost inseparable from dark fermentation [123]. For methanogenesis, methanogens produce $\mathrm{CH}_{4}$ through acetotrophic (Eq. 39; from acetate) or hydrogenotrophic (Eq. 40; from $\mathrm{H}_{2}$ and $\mathrm{CO}_{2}$ ) pathways, where the former indirectly drives the latter by releasing $\mathrm{CO}_{2}$ [110]. To maximise $\mathrm{H}_{2}$ synthesis via VFA acetogenesis, aforesaid $\mathrm{H}_{2}$-utilizing side reactions $\left(\mathrm{CO}_{2}\right.$ acetogenesis, solventogenesis, and methanogenesis) could be suppressed during dark fermentation by adopting high process temperature (reduced gas solubility), near-neutral $\mathrm{pH}$ control 
(dissociation of VFA into non-lipid permeable VFA anions), and low hydraulic retention time (preclusion of slow-growing methanogens from proliferating) [103]. Apart from VFA acetogenesis, the $\mathrm{H}_{2}$ formation from dark fermentation is also governed by formate pathway and NADH pathway [110, 124]. For formate pathway, the formate is enzymatically degraded to $\mathrm{H}_{2}$ and $\mathrm{CO}_{2}$ via formate hydrogen lyase complex (FHL), which consists of formate dehydrogenase (FDH; Eq. 41) and $\mathrm{Fd} \mathrm{H}_{2}$ ase (Eq. 23) [124]. Despite possible formation of formate with the aid of PFL, the formate pathway for $\mathrm{H}_{2}$ production is discouraged by microbial inhibition due to strong acidity of formate [103]. For NADH pathway, $\mathrm{NADH}$ and $\mathrm{H}^{+}$(from glycolysis or pyruvate decarboxylation) are utilised to generate $\mathrm{H}_{2}$ via the combinative action of Fd:NAD ${ }^{+}$oxidoreductase (FNOR; Eq. 42) and Fd $\mathrm{H}_{2}$ ase (Eq. 23) [124]. NADH pathway for $\mathrm{H}_{2}$ synthesis is hampered by the role of NADH as $\mathrm{e}^{-}$carrier in multiple anaerobic metabolisms, sc. (i) lactate fermentation, (ii) propionate fermentation, (iii) butyrate fermentation, and (iv) solventogenesis. Since VFA acetogenesis also partakes in $\mathrm{H}_{2}$ production, the main challenges of NADH pathway are lactate fermentation and solventogenesis, thus genetic alteration might be a potential solution [124].

$$
\begin{aligned}
& \mathrm{CH}_{3} \mathrm{CH}_{2} \mathrm{COOH}+2 \mathrm{H}_{2} \mathrm{O} \rightarrow \mathrm{CH}_{3} \mathrm{COOH}+\mathrm{CO}_{2}+3 \mathrm{H}_{2} \\
& \mathrm{CH}_{3}\left(\mathrm{CH}_{2}\right)_{2} \mathrm{COOH}+2 \mathrm{H}_{2} \mathrm{O} \rightarrow 2 \mathrm{CH}_{3} \mathrm{COOH}+3 \mathrm{H}_{2} \\
& 2 \mathrm{CO}_{2}+4 \mathrm{H}_{2} \leftrightarrow \mathrm{CH}_{3} \mathrm{COOH}+2 \mathrm{H}_{2} \mathrm{O} \\
& \mathrm{CH}_{3} \mathrm{COOH} \rightarrow \mathrm{CH}_{4}+\mathrm{CO}_{2} \\
& \mathrm{CO}_{2}+4 \mathrm{H}_{2} \rightarrow \mathrm{CH}_{4}+2 \mathrm{H}_{2} \mathrm{O} \\
& \mathrm{CH}_{2} \mathrm{O}_{2}+\mathrm{NAD}^{+} \rightarrow{ }^{\mathrm{FDH}} \mathrm{CO}_{2}+\mathrm{NADH}+\mathrm{H}^{+} \\
& \mathrm{NADH}+\mathrm{H}^{+}+\mathrm{Fd}_{\mathrm{Ox}} \rightarrow{ }^{\mathrm{FNOR}} \mathrm{NAD}^{+} \\
& \quad+\mathrm{Fd}_{\text {Red }}(\mathrm{Ox}: \text { Oxidized, Red : Reduced })
\end{aligned}
$$

In photofermentation, the phototrophic microbes first degrade organics to organic acids (VFA) via dark fermentation, then metabolise the VFA to CAC intermediates and polyhydroxyalkanoates (PHA) [104]. Figure 5(b) shows the mechanism for photofermentation of organic acids in purple non-sulfur bacteria. Under light irradiation, purple non-sulfur bacteria able to harness photon energy for photophosphorylation [105]. During light-dependent reactions, phototrophic bacteria perform anoxygenic (without $\mathrm{O}_{2}$ production from photolytic water splitting) and cyclic photophosphorylation, different from oxygenic and non-cyclic photophosphorylation of cyanobacteria and microalgae as in the case of biophotolysis of water [106]. Cyclic photophosphorylation generates the ATP through several steps, which involve (i) effective photon absorption by photosystem (P870) via antenna pigments (chiefly bacteriochlorophylls), (ii) $\mathrm{e}^{-}$photoexcitation of $\mathrm{P} 870$ to $\mathrm{P} 870^{+}$(Eq. 43), (iii) reduction of quinone (Q) to quinol $\left(\mathrm{QH}_{2}\right)$ upon acceptance of $\mathrm{H}^{+}$and $\mathrm{e}^{-}$(Eq. 44), (iv) simultaneous $\mathrm{e}^{-}$transfer and $\mathrm{H}^{+}$release from $\mathrm{QH}_{2}$ to cytochrome $c_{2}$ complex (Cyt $c_{2}$ ) and into periplasm, separately that catalysed by cytochrome $b c_{1}$ complex (Cyt $\left.b c_{1}\right)$ (Eq. 45), (v) $\mathrm{e}^{-}$transfer from Cyt $c_{2}$ back to $\mathrm{P} 870^{+}$(Eq. 46) and (vi) ATP synthesis via ATP synthase (with transmembrane $\mathrm{H}^{+}$ gradient) [107].

$$
\begin{aligned}
& \mathrm{P} 870 \rightarrow{ }^{\mathrm{h} v} \mathrm{P} 870^{+}+\mathrm{e}^{-} \\
& \mathrm{Q}+2 \mathrm{H}^{+}+2 \mathrm{e}^{-} \rightarrow \mathrm{QH}_{2} \\
& \mathrm{QH}_{2}+2\left(\mathrm{Cyt} c_{2}\right)_{\mathrm{Ox}} \rightarrow{ }^{\mathrm{Cyt} b c_{1}} \mathrm{Q}+2\left(\mathrm{Cyt} c_{2}\right)_{\mathrm{Red}} \\
& \quad+2 \mathrm{H}^{+}(\mathrm{Ox}: \text { Oxidized, Red }: \text { Reduced }) \\
& \left(\mathrm{Cyt} c_{2}\right)_{\mathrm{Red}}+\mathrm{P} 870^{+} \rightarrow\left(\mathrm{Cyt} c_{2}\right)_{\mathrm{Ox}} \\
& \quad+\mathrm{P} 870(\mathrm{Ox}: \text { Oxidized, Red : Reduced })
\end{aligned}
$$

In analogous to biophotolysis, the $\mathrm{QH}_{2}$ could also reduce $\mathrm{Fd}$ by donating its $\mathrm{e}^{-}$for subsequent production of $\mathrm{H}_{2}$ (via $\mathrm{N}_{2}$ ase or $\mathrm{H}_{2}$ ase), $\mathrm{NH}_{3}$ (via $\mathrm{N}_{2}$ ase), $\mathrm{NADPH}$ (via FNR), and GAP (via Calvin cycle). Apart from the cyclic photophosphorylation, the reduction of $\mathrm{Q}$ into $\mathrm{QH}_{2}$ is also possible by accepting $\mathrm{e}^{-}$from some organic acids [lactate, pyruvate, and $\mathrm{CAC}$ intermediates (malate and succinate)], NADH (from CAC), and $\mathrm{H}_{2}$, which aided by acid:quinone oxidoreductase (acid dehydrogenase), NADH:quinone oxidoreductase (NADH dehydrogenase), and $\mathrm{H}_{2}$ :quinone oxidoreductase (uptake $\mathrm{H}_{2}$ ase), respectively [106, 125-128]. As uptake $\mathrm{H}_{2}$ ase reverts $\mathrm{H}_{2}$ to $\mathrm{H}^{+}, \mathrm{N}_{2}$ ase outperforms $\mathrm{H}_{2}$ ase in the photofermentative $\mathrm{H}_{2}$ production. In dark fermentation, VFA only being metabolised by slow methanogenesis after acetogenesis [110]. Unlike dark fermentation, the photofermentation allows continuous ATP generation through cyclic photophosphorylation, thus rendering ATP-intensive conversion of VFA (acetate, propionate, and butyrate) into acyl-CoA (acetyl-CoA, propionyl-CoA, and butyryl-CoA) [104]. Figure 5(b) depicts that aforesaid acyl-CoA is either metabolised by CAC or PHA fermentation. For CAC route, both acetyl-CoA and butyryl-CoA enter CAC as citrate while propionyl-CoA enters $\mathrm{CAC}$ as succinyl-CoA, which leads to the synthesis of $\mathrm{e}^{-}$donors for $\mathrm{Q}$ (succinate and malate), $\mathrm{QH}_{2}$, and thereby $\mathrm{H}_{2}$. However, the possible NADPH production during photofermentation restrains $\mathrm{H}_{2}$ production because some VFA may undergo NADPH-depleting PHA fermentation to form polyhydroxybutyrate (PHB from acetate and butyrate), polyhydroxyvalerate (PHV from propionate), and poly(hydroxybutyrate-co-polyhydroxyvalerate) (mixture of PHB and PHV) [104]. Similar to water biophotolysis, photofermentation also requires photon energy supplied from artificial light or solar light. Due to photooxidative stress, phototrophic bacteria exhibit slower growth and $\mathrm{H}_{2}$ production rates than anaerobes in dark fermentation; howbeit, 
photofermentation offers more efficient VFA metabolism [129]. To maximise $\mathrm{H}_{2}$ yield while minimise energy costs (related to the lighting and cooling), the integration of dark fermentation and photofermentation in a sequential manner seems to be promising.

\subsubsection{Microbial electrolysis of organics}

Microbial electrolysis (bioelectrolysis) of organics is another biochemical pathway that generate $\mathrm{H}_{2}$ from anaerobic biodegradation of organics by applying some external voltage to the microbial electrolysis cells (MEC) [130, 131]. Figure 6 illustrates general mechanism for microbial electrolysis of organics in a dual chambered MEC. Generally, dual chambered MEC comprised of an anodic compartment (with wastewater/ organic-laden medium), a cathodic compartment (filled with electrolyte), a bioanode (electrode that coated with biofilm of exoelectrogens), a cathode, a proton exchange membrane (PEM), a conducting wire, and a power source [132]. Both cathode and anode are often fabricated with carbon-based (i.e., graphite, graphene) and noble metal-based materials by virtue of (i) high electrical conductivity, (ii) corrosionresistant (inert towards the oxidation), (iii) high hardness (trivial deformation after prolonged usage), and (iv) high specific surface area (numerous adsorption sites for $\mathrm{e}^{-}$transfer) [133].

Exoelectrogens grown in the anodic compartment of MEC by feeding on organics of wastewater/organic-laden medium, and after some time, they started to deposit on bioanode through biofilm development [62]. During metabolism, the exoelectrogens anaerobically decompose organics (preferably acetate) into $\mathrm{CO}_{2}, \mathrm{H}^{+}$, and $\mathrm{e}^{-}$, where such electrochemically active bacteria able to shuttle $\mathrm{e}^{-}$to bioanode (acts as final $\mathrm{e}^{-}$ acceptor) extracellularly $[132,134]$. Without light irradiation, the biochemistry for the anaerobic oxidation of organics is not yet fully understood; however, it is believed that the endergonic anaerobic oxidation of VFA (acetate, propionate, \& butyrate) are partly integrated with exergonic methanogenesis via syntrophic feeding mode $[135,136]$. Anaerobic oxidation of VFA (Eq. 44) to simpler compounds (i.e., $\mathrm{CO}_{2}$ and etc) eventually releases $\mathrm{H}^{+}$and $\mathrm{e}^{-}$, where (i) $\mathrm{H}^{+}$migrates from anodic compartment to cathodic compartment through $\mathrm{H}^{+}$-

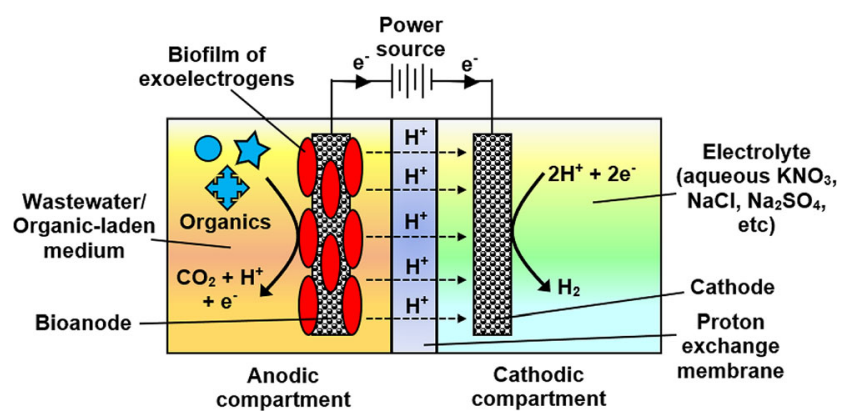

Fig. 6 Mechanism for microbial electrolysis of organics in a dual chambered microbial electrolysis cell (sketched based on [130, 132, 133]) permeable PEM and (ii) $\mathrm{e}^{-}$flows from bioanode to cathode via the external conducting wire [132]. At the cathode, $\mathrm{H}_{2}$ evolution (Eq. 45) occurs if the electrochemical potential is met by anaerobic oxidation of organics [132]. In most circumstances, external voltage has to be supplied because the electrochemical potential is not adequate for $\mathrm{H}_{2}$ evolution; hence, such device is termed as MEC as it integrates microbes (exoelectrogens) and electrolytic cell.

Bioanode : VFA $\rightarrow$ Simpler compounds (i.e., $\mathrm{CO} 2$ and etc) $+\mathrm{H}^{+}+\mathrm{e}^{-}$

Cathode : $2 \mathrm{H}^{+}+2 \mathrm{e}^{-} \rightarrow \mathrm{H}_{2}$

Despite MEC technology grants concurrent wastewater treatment and $\mathrm{H}_{2}$ production, most pilot-scale MEC demonstrated poor $\mathrm{H}_{2}$ production rate $\left(<15 \mathrm{~L} /\left(\mathrm{m}^{2} \cdot \mathrm{d}\right)\right)$, especially if the applied current density of cathode is $<1 \mathrm{~A} / \mathrm{m}^{2}[133,137]$. Furthermore, the cultivation of isolated exoelectrogens in sterilised wastewater could selectively favour $\mathrm{H}_{2}$ production by excluding growth of anaerobes; however, this approach compromises the treatment cost (energy-intensive autoclave sterilization) and degradation efficiency (inability of exoelectrogens to degrade most complex substrates) [138]. For MEC, the minimal external voltage that needed to be supplied often greater than the theoretical potential difference between the anaerobic oxidation of organics and $\mathrm{H}_{2}$ evolution because of internal resistance from the electrolyte (ionic resistance), PEM (diffusion resistance of $\mathrm{H}^{+}$), and conducting wire (diffusion resistance of $\mathrm{e}^{-}$) [131, 132, 137]. Large specific surface area of porous electrodes increases likelihood of clogging via adsorption of organics, thereby reduce the effective contact area for $\mathrm{e}^{-}$transfer [137]. Moreover, acetate is the most studied and effective substrate for $\mathrm{H}_{2}$ synthesis via MEC; therefore, the complex substrates are probably less preferable feedstock $[130,131]$. Despite single-chambered membraneless MEC is possible, the main limitation of such design is the risk of $\mathrm{H}_{2}$ consumption because of methanogenesis [132]. Nevertheless, single chambered membrane-less MEC is economically viable than the dual chambered MEC by eliminating the necessity of costly PEM and the internal resistance of PEM. While most of recent MEC works focus on modification of electrodes, it is advisable that the scrutinisation of biochemistry is utmost important as it narrates the intrinsic limitations of MEC.

\section{Current constraints}

High efficiency generation of biohydrogen from bio-based waste materials is the main advantage identified in investigations of present biological processes which motivated the hydrogen generation processes through these paths. Nonetheless, efforts are needed to sort out the disadvantages of hydrogen generation pathway toward enhancing the 
generation processes in order to shift the economy towards hydrogen energy dependence from fossil fuel based. According to Momirlan and Veziroglu [139], the opposing challenges in production and application of biohydrogen are lower conversion rates, higher processing cost, stockpiling, distribution, transport and delivery etc. Both compression and liquefaction are taken into consideration while reviewing hydrogen conditioning as these factors are also practicable in the sense of commercial feasibility. However, the presence of these factors acted as emerging threats in opposition to the demand of hydrogen as an attractive transportation fuel if they are executed for ample advancements and improvements. Figure 7 outlines the critical concerns in introducing hydrogen for transportation.

Nevertheless, numeral concerns are associated to the safe and sound execution of the hydrogen economy such as safety at all stages of the distribution usage along with any disposal hydrogen gas and up-scaling of pilot-scale operations. Hence, massive number of researches should be conducted so that hydrogen gas can be regarded as an encouraging fuel in the near future via various technologies such as photo-fermentation, water electrolysis and dark fermentation with more focus on easy operation, high sustainability, low energy demand, and high generation rate. Nowadays, the cost of hydrogen produced through biologically approaches emerges to be more expensive than other biofuels. Thus, numerous technical and engineering challenges required should be tackled before consideration of economic barriers [140]. High-throughput analyses play a critical part in biohydrogen fermentation processes, in order to achieve dependable information for scale-up studies. Novel reactor designs with high levels of assimilation integrated with online computer systems are needed to access the drastic operation setting during the procedure. Mathematical and statistical tools are also critical to

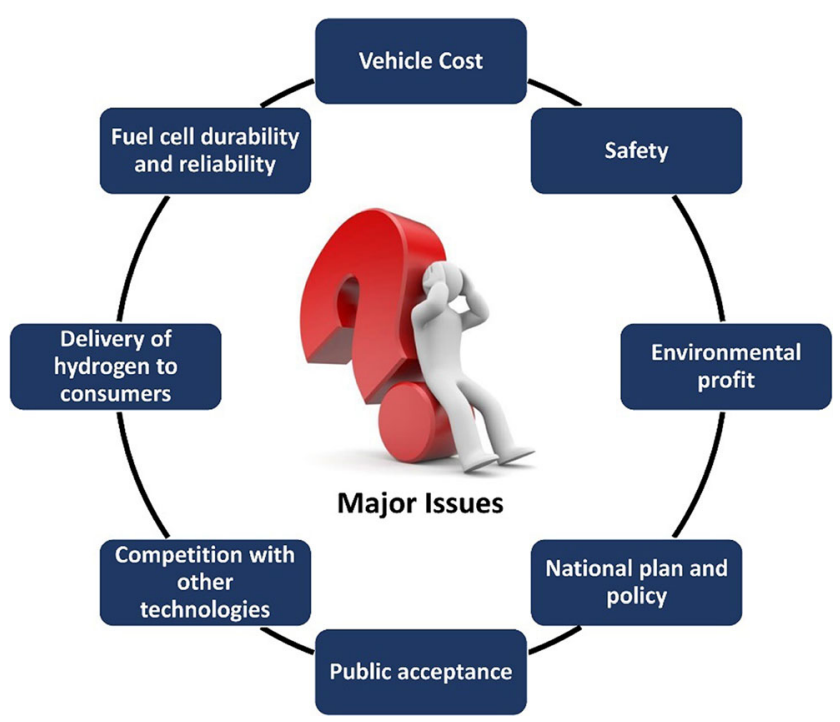

Fig. 7 Major issues in introduction of hydrogen as fuel in transportation accommodate analysis on the synergistic consequences of different elements on the overall yield in biohydrogen fermentation mechanisms [141].

Shao et al. [142] proposed that generation of hydrogen through biological process is the leading platform to execute pilot-scale green development. However, it is necessary to develop the central metabolic process of microbes through anaerobic fermentation as it indicates the pathways of hydrogen generation which makes it easier to understand the operation involved. Remarkable enhancements can be predicted via the evolution of advanced bioreactor designing and genetically engineered thermophilic fermentative microorganism which eventually triumphs the sustainable production of hydrogen at a commercial level. However, an in-depth interdisciplinary collaboration to verify necessary synergies for the evolution of a commercial thermophilic hydrogen generation process is required to overcome most of the current challenges, whereby the outcomes of economic feasibility may probably show that thermophilic biological hydrogen production is ideally suited into a bio-refinery process.

Despite adequate discovery through scientific research and significant momentum in enhancing the production rate of biohydrogen, there are only finite research knowledge accessible on its economics while reviewing paths for commercialization [143]. Construction and development of the bioreactor and the designation of assembly systems for exploiting biohydrogen demonstrate to be final during estimation and analysis of cost. Distribution and storage issues, performance, environmental profits, cost, rules and legislation and national plan and policy are the principal issues in establishing hydrogen as a fuel which also affect consumer options through stimulation of the use of hydrogen [144].

Implementation of biological tools in production of hydrogen is the triumph threat for biotechnology which highlights the present and unknown future environmental issues [145]. The prospective field of biological mode of hydrogen production is not only fixed by scientific precursors such as designing of bioreactor and altering microorganisms genetic for competency improvement with consideration of societal acceptance, economics as well as the progress in systems for hydrogen energy [146]. Thorough demonstrations of technology are essential for hydrogen generation from biomass to solve considerable challenges to form economically competitive [147]. Futuristic outline to improve operating conditions such as $\mathrm{pH}$, temperature, substrate choice, bioreactor alterations, organic loading rate, strain selection and nutrient enrichments, hydraulic retention time, metabolic construction of biohydrogen pathways, and microbial immobilization are required for biohydrogen acquirement improvement [148, 149]. Evolution in fuel cell stimulates, prompts utilisation of hydrogen for transport, domestic, industrial, and thermal energy requirements. Emergent techniques are expected to turn up for reduced rate, cost, and transformation of hydrogen when 
harnessed in industrial scale [35] Thus, it is the right moment for the execution of advanced technologies which are renewable and sustainable with carbon negative in nature to tackle the current world energy issues [95].

\section{Case studies of B-HPPs}

In this review, two distinct HPPs, namely thermochemical conversion and biochemical conversion routes were succinctly discussed in detail. Although production of hydrogen is largely inclined towards carbon intensive processes at present [17], its production, especially from renewable source, has been rapidly gaining momentum in recent years. For thermochemical conversion route, pilot-scale projects are more inclined towards the application of biomass gasification process. In Asia region, the development of gasification plants in China is often positioned at electricity-scarce regions to develop the local socio-economic status. The utilisation of biomass, especially agricultural wastes, in these locations is more feasible due to the lower investment costs and smaller plant units varying less than $200 \mathrm{~kW}$ to $3 \mathrm{MW}$ [150]. For small-tomedium-scale biomass gasification systems, Hefei Tianyan Green Energy Development Co. Ltd. (Tianyan) and Guangzhou Institute of Energy Conversion (GIEC) stood out [150] particularly. Tianyan employs down-draft fixed bed gasifiers for engine capacity below $200 \mathrm{~kW}$ while fluidised bed gasifier is utilised for capacity above $400 \mathrm{~kW}$. In contrast, GIEC developed and adopted circulating fluidised bed biomass gasification power with capacities ranging between $800 \mathrm{~kW}$ to $1000 \mathrm{~kW}$. For larger scale systems, a biomass integrated gasification combined cycle (IGCC) system with steam turbine generator capacity of $1.5 \mathrm{MW}$ and gas engine generator of 4MW capacity were deployed by GIEC.

In Malaysia, palm oil-based agricultural wastes are often used as feedstocks of choice. The country's first biomass power plant to be connected to the grid is by TSH Resources Sdn. Bhd. located at Kunak, Sabah, with a generation capacity of 14 MW using empty fruit bunch (EFB). Under the ECASEAN COGEN program, other three full scale demonstration projects were also established in Malaysia, including Kumpulan Guthrie Berhad (2 MW cogeneration plant with oil palm fibers and shells feedstocks), Bumi Biopower Sdn. Bhd. (6 MW cogeneration plant with EFB and shells feedstocks) and Kilang Beras Co. Titi Serong Sdn. Bhd. (1.5 MW rice-fired cogeneration plant) [151]. In Eastern part of Indonesia, biomass gasification plant with $700 \mathrm{~kW}$ capacity based on bamboo feedstock is expected to be built in Mentawai under the Clean Power Indonesia (CPI) programme. Through this programme, 3,000 tonnes $/ \mathrm{CO}_{2}$ emission per year is avoided whilst improving electricity access for commercial and productive uses [152]. In addition, $25 \mathrm{~kW}$ biomass gasification pilot plant was constructed in
Jogjakarta, Indonesia, and was further upscaled to $135 \mathrm{~kW}$ with the support of New Energy and Industrial Technology Development Organization, Japan (NEDO) in 2008 [153]. Clay catalyst was used to convert palm oil biomass efficiently under fluidised condition into gas and char. By-products from spent catalyst and ash mixture is obtained and be applied back to soil for sustainable farming applications.

Nevertheless, technological progress and applicability of biochemical conversion routes to produce hydrogen are still at its infancy stage. To date, there are no clear pilot scale or demonstration scale projects available and its current stage is mainly at developmental phase. Heidrich et al. [154] had operated $100 \mathrm{~L}$ MEC to produce hydrogen gas from raw domestic wastewater. In their findings, gas production rates with an average of $0.6 \mathrm{~L} /$ day hydrogen production declined with time while remain unaffected by low temperatures. In terms of electrical energy input, an average of $48.7 \%$ was recovered with Coulombic efficiency below required standards [154]. Lin et al. [155] operated a pilot-scale fermenter with $0.60 \mathrm{~m}^{3}$ to $0.75 \mathrm{~m}^{3}$ tank volumes with organic loading rate (OLR) between 40 to $240 \mathrm{~kg} / \mathrm{COD} / \mathrm{m}^{3} / \mathrm{d}$. In their findings, hydrogen production improved at higher OLR, where a maximum hydrogen production rate of $15.59 \mathrm{~m}^{3} / \mathrm{m}^{3} / \mathrm{d}$ was achievable. Similarly, Gottardo et al. [156] had performed pilot scale fermentation coupled with anaerobic digestion of food waste with $230 \mathrm{~L}$ one-stage digester integrated with a two-stage process $200 \mathrm{~L}$ fermentation unit and $380 \mathrm{~L}$ digester unit. In their study, proper recycling flow management is imperative to ensure $\mathrm{pH}$ values do not deviate away from its optimal values (5.5). In terms of hydrogen production, they were able to obtain a maximum of $40 \%$ hydrogen at $170 \mathrm{~L} / \mathrm{kg}$ total volatile solids.

\section{Conclusion}

Biohydrogen, or green hydrogen, is a promising energy carrier which can complement the existing fossil fuel economy to meet the ever-growing global energy demands. To reduce the dependency on fossil fuels for production of hydrogen, the alternative is to fully utilise available biomass waste feedstocks via waste decomposition technologies through both thermochemical and biochemical conversion routes. Currently, technical, and economic barriers continue to outweigh the production technologies outlined in B-HPPs. Multiple process considerations, such as environmental sensitivity factors, feedstock conditions, and efficacy of catalysts, need to be considered to ensure biohydrogen production is competitive and viable against current conventional production methods and non-conventional production technologies from renewable sources such as electrolysis and solar energy. At present, the feasibility for biohydrogen production is more inclined towards thermochemical conversion pathway with 
multiple demonstration scale projects readily operational. On the other hand, biochemical conversion-based technologies are still widely considered at its infant stage and requirefurther research and development to make the process more viable. Furthermore, extensive research works comprising of multidisciplines are encouraged to further tackle the current constraints faced, ranging from safety to policymaking, to effectively produce and deploy biohydrogen energy source. By overcoming the aforementioned limitations, only then a full transition towards a sustainable hydrogen-based economy can be achieved.

Acknowledgements The authors would like to gratefully express their sincere appreciation for the financial support awarded by Ministry of Higher Education, Malaysia (015MA0-052 \& 015MA0-104) and conferment of HICoE award to Centre for Biofuel and Biochemical Research (HICoE-CBBR), Universiti Teknologi PETRONAS is duly acknowledged.

Author contribution Yee Ho Chai had conceptualised the idea for this review article, performed compilation of the review article and review and editing of the review article. Literature research and data analysis were contributed by Dr Mustakimah Mohamed, Dr Cheng Yoke Wang, Dr Bridgid Lai Fui Chin and Dr Chung Loong Yiin. Prof Dr Suzana Yusup reviewed and edited the article and Dr Lam Man Kee reviewed the article.

\section{References}

1. Ediger VS, Akar S (2007) ARIMA forecasting of primary energy demand by fuel in Turkey. Energy Policy 35:1701-1708. https:// doi.org/10.1016/j.enpol.2006.05.009

2. Ediger VȘ, Akar S, Uğurlu B (2006) Forecasting production of fossil fuel sources in Turkey using a comparative regression and ARIMA model. Energy Policy 34:3836-3846. https://doi.org/10. 1016/j.enpol.2005.08.023

3. Asif M, Muneer T (2007) Energy supply, its demand and security issues for developed and emerging economies. Renew Sustain Energy Rev 11:1388-1413. https://doi.org/10.1016/j.rser.2005. 12.004

4. Shafiee S, Topal E (2009) When will fossil fuel reserves be diminished? Energy Policy 37:181-189. https://doi.org/10.1016/j. enpol.2008.08.016

5. IEA (2020) Global CO2 emissions in 2019. Paris

6. IEA (2017) Global CO2 emissions by sector. Paris

7. Petinrin JO, Shaaban M (2015) Renewable energy for continuous energy sustainability in Malaysia. Renew Sustain Energy Rev 50: 967-981. https://doi.org/10.1016/j.rser.2015.04.146

8. Mujiyanto S, Tiess G (2013) Secure energy supply in 2025: Indonesia's need for an energy policy strategy. Energy Policy 61:31-41. https://doi.org/10.1016/j.enpol.2013.05.119

9. Wattana S (2014) Bioenergy development in Thailand: Challenges and strategies. Energy Procedia 52:506-515. https:// doi.org/10.1016/j.egypro.2014.07.104

10. Fay M, Hallegatte S, Vogt-Schilb A, et al (2015) Decarbonizing development: three steps to a zero-carbon future

11. Ball M, Wietschel M (2009) The future of hydrogen - opportunities and challenges. Int J Hydrogen Energy 34:615-627. https:// doi.org/10.1016/j.ijhydene.2008.11.014
12. Zhang Z, Wang Y, Hu J, Wu Q, Zhang Q (2015) Influence of mixing method and hydraulic retention time on hydrogen production through photo-fermentation with mixed strains. Int $\mathrm{J}$ Hydrogen Energy 40:6521-6529. https://doi.org/10.1016/j. ijhydene.2015.03.118

13. Niaz S, Manzoor T, Pandith AH (2015) Hydrogen storage: Materials, methods and perspectives. Renew Sustain Energy Rev 50:457-469. https://doi.org/10.1016/j.rser.2015.05.011

14. Sgobbi A, Nijs W, De Miglio R et al (2016) How far away is hydrogen? Its role in the medium and long-term decarbonisation of the European energy system. Int J Hydrogen Energy 41:19-35. https://doi.org/10.1016/j.ijhydene.2015.09.004

15. Pudukudy M, Yaakob Z, Mohammad M, Narayanan B, Sopian K (2014) Renewable hydrogen economy in Asia - Opportunities and challenges: An overview. Renew Sustain Energy Rev 30:743757. https://doi.org/10.1016/j.rser.2013.11.015

16. Nicita A, Maggio G, Andaloro APF, Squadrito G (2020) Green hydrogen as feedstock: Financial analysis of a photovoltaicpowered electrolysis plant. Int J Hydrogen Energy 45:1139511408. https://doi.org/10.1016/j.ijhydene.2020.02.062

17. Franchi G, Capocelli M, De Falco M et al (2020) Hydrogen production via steam reforming: A critical analysis of MR and RMM technologies. Membranes (Basel) 10. https://doi.org/10.3390/ membranes 10010010

18. Bildirici ME, Özaksoy F (2013) The relationship between economic growth and biomass energy consumption in some European countries. J Renew Sustain Energy 5:1-10. https://doi. org/10.1063/1.4802944

19. Demirbaş A (2001) Biomass resource facilities and biomass conversion processing for fuels and chemicals. Energy Convers Manag 42:1357-1378. https://doi.org/10.1016/S0196-8904(00) 00137-0

20. Kapdan IK, Kargi F (2006) Bio-hydrogen production from waste materials. Enzyme Microb Technol 38:569-582. https://doi.org/ 10.1016/j.enzmictec.2005.09.015

21. Ren J, Toniolo S (2018) Life cycle sustainability decision-support framework for ranking of hydrogen production pathways under uncertainties: An interval multi-criteria decision making approach. J Clean Prod 175:222-236. https://doi.org/10.1016/j.jclepro.2017. 12.070

22. Dou B, Zhang H, Song Y, Zhao L, Jiang B, He M, Ruan C, Chen $\mathrm{H}, \mathrm{Xu}$ Y (2019) Hydrogen production from the thermochemical conversion of biomass: Issues and challenges. Sustain Energy Fuels 3:314-342. https://doi.org/10.1039/c8se00535d

23. James AMR, Yuan W, Boyette MD (2016) The Effect of Biomass Physical Properties on Top-Lit Updraft Gasification of Woodchips. Energies 9:283. https://doi.org/10.3390/en9040283

24. Ritchie H Energy Production and Consumption. In: Our World Data. https://ourworldindata.org/energy-production-consumption. Accessed 30 Jan 2020

25. Sönnichse N (2020) Cost of coal and natural gas for electric generation in the United States from 1980 to 2019*. In: Statista. https://www.statista.com/statistics/189180/natural-gas-vis-a-viscoal-prices/. Accessed 30 Dec 2020

26. Karkour S, Ichisugi Y, Abeynayaka A, Itsubo N (2020) Externalcost estimation of electricity generation in G20 countries: Case study using a global life-cycle impact-assessment method. Sustain 12:. https://doi.org/10.3390/su12052002

27. International Renewable Energy Agency (IRENA) (2019) Renewable Power Generation Costs in 2019. https://www.irena. org/publications/2020/Jun/Renewable-Power-Costs-in-2019. Accessed 30 Dec 2020

28. Sönnichsen N (2020) Electricity production costs for nuclear power plants in the United States from 2002 to 2019. In: Statista. https://www.statista.com/statistics/184754/cost-of-nuclear- 
electricity-production-in-the-us-since-2000/. Accessed 30 Dec 2020

29. (IRENA) IREA (2020) Renewable capacity highlights

30. Hosseini SE, Wahid MA, Ganjehkaviri A (2015) An overview of renewable hydrogen production from thermochemical process of oil palm solid waste in Malaysia. Energy Convers Manag 94:415429. https://doi.org/10.1016/j.enconman.2015.02.012

31. Meher Kotay S, Das D (2008) Biohydrogen as a renewable energy resource-Prospects and potentials. Int J Hydrogen Energy 33:258 263. https://doi.org/10.1016/j.ijhydene.2007.07.031

32. Demirbas A (2009) Global renewable energy projections. Energy Sources, Part B Econ Plan Policy 4:212-224. https://doi.org/10. 1080/15567240701620499

33. ERIA (2019) The Potential and Costs of Hydrogen Supply. Demand Supply Potential Hydrog Energy East Asia, ERIA Res Proj Rep FY2018 140-183

34. Prabakar D, Manimudi VT, Suvetha KS et al (2018) Advanced biohydrogen production using pretreated industrial waste: Outlook and prospects. Renew Sustain Energy Rev 96:306-324. https://doi.org/10.1016/j.rser.2018.08.006

35. Preethi, Usman TMM, Rajesh Banu J et al (2019) Biohydrogen production from industrial wastewater: An overview. Bioresour Technol Reports 7:100287. https://doi.org/10.1016/j.biteb.2019. 100287

36. Jiménez-Llanos J, Ramírez-Carmona M, Rendón-Castrillón L, Ocampo-López C (2020) Sustainable biohydrogen production by Chlorella sp. microalgae: A review. Int J Hydrogen Energy 45:8310-8328. https://doi.org/10.1016/j.jhydene.2020.01.059

37. Akhtar A, Krepl V, Ivanova T (2018) A Combined Overview of Combustion, Pyrolysis, and Gasification of Biomass. Energy and Fuels 32:7294-7318. https://doi.org/10.1021/acs.energyfuels. $8 \mathrm{~b} 01678$

38. Luo Z, Zhou J (2012) Thermal Conversion of Biomass. In: Chen W-Y, Seiner J, Suzuki T, Lackner M (eds) Handbook of Climate Change Mitigation and Adaptation, Second Edi. Springer, New York, pp 1002-1037

39. Patel M, Zhang X, Kumar A (2016) Techno-economic and life cycle assessment on lignocellulosic biomass thermochemical conversion technologies: A review. Renew Sustain Energy Rev 53: 1486-1499. https://doi.org/10.1016/j.rser.2015.09.070

40. Mohan D, Sarswat A, Sik Y, Pittman CU (2014) Organic and inorganic contaminants removal from water with biochar, a renewable, low cost and sustainable adsorbent - A critical review. Bioresour Technol 160:191-202. https://doi.org/10.1016/j. biortech.2014.01.120

41. Jaffar MM, Nahil MA, Williams PT (2020) Synthetic natural gas production from the three stage (i) pyrolysis (ii) catalytic steam reforming (iii) catalytic hydrogenation of waste biomass. Fuel Process Technol 208:106515. https://doi.org/10.1016/j.fuproc. 2020.106515

42. Jahirul MI, Rasul MG, Chowdhury AA, Ashwath N (2012) Biofuels production through biomass pyrolysis- A technological review. Energies 5:4952-5001. https://doi.org/10.3390/ en5124952

43. Bakhtyari A, Makarem MA, Rahimpour MR (2018) Hydrogen Production Through Pyrolysis. Encycl Sustain Sci Technol:128. https://doi.org/10.1007/978-1-4939-2493-6_956-1

44. Tursi A (2019) A review on biomass: Importance, chemistry, classification, and conversion. Biofuel Res J 6:962-979. https://doi. org/10.18331/BRJ2019.6.2.3

45. Arregi A, Lopez G, Amutio M, Barbarias I, Bilbao J, Olazar M (2016) Hydrogen production from biomass by continuous fast pyrolysis and in-line steam reforming. RSC Adv 6:2597525985. https://doi.org/10.1039/c6ra01657j
46. Parthasarathy P, Narayanan SK (2014) Effect of Hydrothermal Carbonization Reaction Parameters on. Environ Prog Sustain Energy 33:676-680. https://doi.org/10.1002/ep.11974

47. Wu C, Williams PT (2014) Hydrogen from waste plastics by way of pyrolysis-gasification. Proc Inst Civ Eng Waste Resour Manag 167:35-46. https://doi.org/10.1680/warm.13.00006

48. Duman G, Yanik J (2017) Two-step steam pyrolysis of biomass for hydrogen production. Int J Hydrogen Energy 42:17000 17008. https://doi.org/10.1016/j.ijhydene.2017.05.227

49. Prasertcharoensuk P, Bull SJ, Phan AN (2019) Gasification of waste biomass for hydrogen production: Effects of pyrolysis parameters. Renew Energy 143:112-120. https://doi.org/10.1016/j. renene.2019.05.009

50. Hossain A, Ganesan P, Jewaratnam J, Chinna K (2017) Optimization of process parameters for microwave pyrolysis of oil palm fiber (OPF) for hydrogen and biochar production. Energy Convers Manag 133:349-362. https://doi.org/10.1016/j. enconman.2016.10.046

51. Kaushika ND, Reddy KS, Kaushik K (2016) Sustainable energy and the environment: A clean technology approach

52. Ibrahim AA (2018) Hydrogen Production from Light Hydrocarbons. In: Intech Open. pp 39-62

53. El-Mashad HM, Zhang R (2019) Advances in Plant-Based Wasteto-Energy Conversion Technologies. Byprod from Agric Fish 369-402. https://doi.org/10.1002/9781119383956.ch16

54. Nussbaumer T (2003) Combustion and Co-combustion of Biomass: Fundamentals, Technologies and Primary Measures for Emission Reduction. Energy \& Fuels 17:1510-1521. https:// doi.org/10.1021/ef030031q

55. Adams P, Bridgwater T, Lea-Langton A, et al (2018) Biomass Conversion Technologies. Report to NNFCC. Elsevier Inc.

56. Henne RA, Brand MA, Schveitzer B, Schein VAS (2019) Thermal behavior of forest biomass wastes produced during combustion in a boiler system. Rev Arvore 43:1-9. https://doi.org/10. 1590/1806-90882019000100008

57. Isaac K, Bada SO (2020) The co-combustion performance and reaction kinetics of refuse derived fuels with South African high ash coal. Heliyon 6:e03309. https://doi.org/10.1016/j.heliyon. 2020.e03309

58. Bermudez JM, Fidalgo B (2016) Production of bio-syngas and bio-hydrogen via gasification

59. Kirkels AF, Verbong GPJ (2011) Biomass gasification: Still promising? A 30-year global overview. Renew Sustain Energy Rev 15:471-481. https://doi.org/10.1016/j.rser.2010.09.046

60. Anniwaer A, Yu T, Chaihad N, Situmorang YA, Wang C, Kasai Y, Abudula A, Guan G (2020) Steam gasification of marine biomass and its biochars for hydrogen-rich gas production. Biomass Convers Biorefinery. https://doi.org/10.1007/s13399-020-00868$\mathrm{x}$

61. Xiao Y, Xu S, Song Y, Shan Y, Wang C, Wang G (2017) Biomass steam gasification for hydrogen-rich gas production in a decoupled dual loop gasification system. Fuel Process Technol 165:54-61. https://doi.org/10.1016/j.fuproc.2017.05.013

62. Beneroso D, Bermúdez JM, Arenillas A, Menéndez JA (2014) Integrated microwave drying, pyrolysis and gasification for valorisation of organic wastes to syngas. Fuel 132:20-26. https:// doi.org/10.1016/j.fuel.2014.04.064

63. Mirmoshtaghi G (2016) Biomass gasification in fluidized bed gasifiers; Modeling and simulation. Malardalen University

64. Kirkels AF, Verbong GPJ (2011) Biomass gasification: Still promising? A 30-year global overview. Renew Sustain Energy Rev 15:471-481. https://doi.org/10.1016/j.rser.2010.09.046

65. Kumar M, Olajire Oyedun A, Kumar A (2018) A review on the current status of various hydrothermal technologies on biomass feedstock. Renew Sustain Energy Rev 81:1742-1770. https:// doi.org/10.1016/j.rser.2017.05.270 
66. Kipcak E, Akgun M (2015) Hydrogen Production by Supercritical Water Gasification of Biomass. In: Fang Z, Jr. RS, Qi X (eds) Production of Hydrogen from Renewable Resources, 1st ed. Springer Netherlands, Netherland, pp 179-220

67. Susanti RF, Kim J, Yoo K ung (2014) Supercritical Water Gasification for Hydrogen Production: Current Status and Prospective of High-Temperature Operation. Elsevier B.V.

68. Ministry of Agriculture, Forestry, and Fisheries J (2008) The Asian Biomass Handbook Support Project for Building AsianPartnership for. Japan Inst Energy 338

69. Miyata Y, Sagata K, Yamazaki Y, Teramura H, Hirano Y, Ogino C, Kita Y (2018) Mechanism of the Fe-Assisted Hydrothermal Liquefaction of Lignocellulosic Biomass. Ind Eng Chem Res 57: 14870-14877. https://doi.org/10.1021/acs.iecr.8b03725

70. Kumar M, Oyedun AO, Kumar A (2019) Biohydrogen production from bio-oil via hydrothermal liquefaction, 2nd ed. Elsevier Inc.

71. Okolie JA, Rana R, Nanda S, Dalai AK, Kozinski JA (2019) Supercritical water gasification of biomass: A state-of-the-art review of process parameters, reaction mechanisms and catalysis. Sustain Energy Fuels 3:578-598. https://doi.org/10.1039/ c8se00565f

72. Gollakota ARK, Kishore N, Gu S (2018) A review on hydrothermal liquefaction of biomass. Renew Sustain Energy Rev 81:13781392. https://doi.org/10.1016/j.rser.2017.05.178

73. Ahmad SFK, Md Ali UF, Isa KM (2019) Compilation of liquefaction and pyrolysis method used for bio-oil production from various biomass: A review. Environ Eng Res 25:18-28. https:// doi.org/10.4491/eer.2018.419

74. Cheng YW, Chong CC, Lee SP, Lim JW, Wu TY, Cheng CK (2020) Syngas from palm oil mill effluent (POME) steam reforming over lanthanum cobaltite: Effects of net-basicity. Renew Energy 148:349-362. https://doi.org/10.1016/j.renene. 2019.10.040

75. Foong SY, Liew RK, Yang Y, Cheng YW, Yek PNY, Wan Mahari WA, Lee XY, Han CS, Vo DVN, van le Q, Aghbashlo M, Tabatabaei M, Sonne C, Peng W, Lam SS (2020) Valorization of biomass waste to engineered activated biochar by microwave pyrolysis: Progress, challenges, and future directions. Chem Eng J 389:124401. https://doi.org/10.1016/j.cej.2020.124401

76. Kossalbayev BD, Tomo T, Zayadan BK, Sadvakasova AK, Bolatkhan K, Alwasel S, Allakhverdiev SI (2020) Determination of the potential of cyanobacterial strains for hydrogen production. Int J Hydrogen Energy 45:2627-2639. https://doi.org/10.1016/j. ijhydene.2019.11.164

77. Dudek M, Dębowski M, Zieliński M, Nowicka A, Rusanowska P (2018) Water from the Vistula Lagoon as a medium in mixotrophic growth and hydrogen production by Platymonas subcordiformis. Int J Hydrogen Energy 43:9529-9534. https:// doi.org/10.1016/j.ijhydene.2018.04.039

78. Policastro G, Luongo V, Fabbricino M (2020) Biohydrogen and poly- $\beta$-hydroxybutyrate production by winery wastewater photofermentation: Effect of substrate concentration and nitrogen source. J Environ Manage 271:111006. https://doi.org/10.1016/j. jenvman.2020.111006

79. Cieciura-Włoch W, Borowski S, Domański J (2020) Dark fermentative hydrogen production from hydrolyzed sugar beet pulp improved by iron addition. Bioresour Technol 314:123713. https:// doi.org/10.1016/j.biortech.2020.123713

80. Prajapati KB, Singh R (2020) Bio-electrochemically hydrogen and methane production from co-digestion of wastes. Energy 198:117259. https://doi.org/10.1016/j.energy.2020.117259

81. Jayabalan T, Manickam M, Naina Mohamed S (2020) NiCo2O4graphene nanocomposites in sugar industry wastewater fed microbial electrolysis cell for enhanced biohydrogen production. Renew Energy 154:1144-1152. https://doi.org/10.1016/j.renene.2020.03. 071
82. Hallenbeck PC, Benemann JR (2002) Biological hydrogen production; Fundamentals and limiting processes. Int $\mathrm{J}$ Hydrogen Energy 27:1185-1193. https://doi.org/10.1016/S0360-3199(02) 00131-3

83. Rossi F, Filipponi M (2011) Hydrogen production from biological systems under different illumination conditions. Int J Hydrogen Energy 36:7479-7486. https://doi.org/10.1016/j.ijhydene.2011. 03.124

84. Vargas SR, dos Santos PV, Giraldi LA, et al (2018) Anaerobic phototrophic processes of hydrogen production by different strains of microalgae Chlamydomonas sp. FEMS Microbiol Lett 365: https://doi.org/10.1093/femsle/fny073

85. Hoshino T, Johnson DJ, Scholz M, Cuello JL (2013) Effects of implementing PSI-light on hydrogen production via biophotolysis in Chlamydomonas reinhardtii mutant strains. Biomass and Bioenergy 59:243-252. https://doi.org/10.1016/j.biombioe.2013. 09.004

86. Scoma A, Durante L, Bertin L, Fava F (2014) Acclimation to hypoxia in Chlamydomonas reinhardtii: Can biophotolysis be the major trigger for long-term H2 production? New Phytol 204: 890-900. https://doi.org/10.1111/nph.12964

87. Melnicki MR, Pinchuk GE, Hill EA, et al (2012) Sustained H2 Production Driven by Photosynthetic Water Splitting in a Unicellular Cyanobacterium. MBio 3:. https://doi.org/10.1128/ mBio.00197-12.Editor

88. Scoma A, Krawietz D, Faraloni C, Giannelli L, Happe T, Torzillo G (2012) Sustained H 2 production in a Chlamydomonas reinhardtii D1 protein mutant. J Biotechnol 157:613-619. https:// doi.org/10.1016/j.jbiotec.2011.06.019

89. Huesemann MH, Hausmann TS, Carter BM, Gerschler JJ, Benemann JR (2010) Hydrogen generation through indirect biophotolysis in batch cultures of the nonheterocystous nitrogenfixing cyanobacterium plectonema boryanum. Appl Biochem Biotechnol 162:208-220. https://doi.org/10.1007/s12010-0098741-6

90. Dickson DJ, Page CJ, Ely RL (2009) Photobiological hydrogen production from Synechocystis sp. PCC 6803 encapsulated in silica sol-gel. Int J Hydrogen Energy 34:204-215. https://doi. org/10.1016/j.ijhydene.2008.10.021

91. Batyrova K, Hallenbeck PC (2017) Hydrogen production by a Chlamydomonas reinhardtii strain with inducible expression of photosystem II. Int J Mol Sci 18. https://doi.org/10.3390/ ijms 18030647

92. Tamburic B, Zemichael FW, Maitland GC, Hellgardt K (2012) A novel nutrient control method to deprive green algae of sulphur and initiate spontaneous hydrogen production. Int J Hydrogen Energy 37:8988-9001. https://doi.org/10.1016/j.ijhydene.2012. 02.043

93. Benemann JR (2000) Hydrogen production by microalgae. J Appl Phycol 12:291-300. https://doi.org/10.1023/a:1008175112704

94. Kossalbayev B, Tomo T, Zayadan B et al (2019) Determination of the potential of cyanobacterial strains for hydrogen production. Int J Hydrogen Energy 45:2627-2639. https://doi.org/10.1016/j. ijhydene.2019.11.164

95. Mona S, Kumar SS, Kumar V, Parveen K, Saini N, Deepak B, Pugazhendhi A (2020) Green technology for sustainable biohydrogen production (waste to energy): A review. Sci Total Environ 728:138481. https://doi.org/10.1016/j.scitotenv.2020. 138481

96. Abo-Hashesh M, Hallenbeck PC (2012) Microaerobic dark fermentative hydrogen production by the photosynthetic bacterium, Rhodobacter capsulatus JP91. Int J Low-Carbon Technol 7:97103. https://doi.org/10.1093/ijlct/cts011

97. Madamwar D, Garg N, Shah V (2000) Cyanobacterial hydrogen production. World J Microbiol Biotechnol 16:757-767. https:// doi.org/10.1023/A:1008919200103 
98. Khetkorn W, Rastogi RP, Incharoensakdi A, Lindblad P, Madamwar D, Pandey A, Larroche C (2017) Microalgal hydrogen production - A review. Bioresour Technol 243:1194-1206. https://doi.org/10.1016/j.biortech.2017.07.085

99. Giuffrè A, Borisov VB, Arese M, Sarti P, Forte E (2014) Cytochrome bd oxidase and bacterial tolerance to oxidative and nitrosative stress. Biochim Biophys Acta - Bioenerg 1837:11781187. https://doi.org/10.1016/j.bbabio.2014.01.016

100. Tsygankov AA, Kosourov SN, Tolstygina IV et al (2006) Hydrogen production by sulfur-deprived Chlamydomonas reinhardtii under photoautotrophic conditions. Int J Hydrogen Energy 31:1574-1584. https://doi.org/10.1016/j.ijhydene.2006. 06.024

101. Mohan SV, Mohanakrishna G, Srikanth S (2011) Biohydrogen production from industrial effluents, 1st ed. Elsevier Inc.

102. Sun Y, He J, Yang G, Sun G, Sage V (2019) A review of the enhancement of bio-hydrogen generation by chemicals addition. Catalysts 9. https://doi.org/10.3390/cata19040353

103. Cheng Y, Chong C, Lam M et al (2021) Identification of microbial inhibitions and mitigation strategies towards cleaner bioconversions of palm oil mill effluent (POME): A review. J Clean Prod 280:124346. https://doi.org/10.1016/j.jclepro.2020.124346

104. Fradinho JC, Oehmen A, Reis MAM (2014) Photosynthetic mixed culture polyhydroxyalkanoate (PHA) production from individual and mixed volatile fatty acids (VFAs): Substrate preferences and co-substrate uptake. J Biotechnol 185:19-27. https:// doi.org/10.1016/j.jbiotec.2014.05.035

105. Adessi A, Philippis DR (2014) Photosynthesis and Hydrogen Production in Purple Non Sulfur Bacteria: Fundamental and Applied Aspects. In: Microbial BioEnergy: Hydrogen Production. Springer, Dordrecht

106. Adessi A, De Philippis R (2014) Photobioreactor design and illumination systems for $\mathrm{H} 2$ production with anoxygenic photosynthetic bacteria: A review. Int J Hydrogen Energy 39:3127-3141. https://doi.org/10.1016/j.ijhydene.2013.12.084

107. Madigan MM, Bender KS, Buckley D, et al (2014) Brock Biology of Microorganisms. Pearson

108. Wijffels RH, Barten H, Reith RH (2003) Bio-methane and biohydrogen : status and perspectives of biological methane and hydrogen production. Dutch Biological Hydrogen Foundation NOVEM, The Hague, The Netherlands

109. Dahiya S, Kumar AN, Shanthi Sravan J, et al (2018) Food waste biorefinery: Sustainable strategy for circular bioeconomy. Elsevier Ltd

110. Lam MK, Lee KT (2011) Renewable and sustainable bioenergies production from palm oil mill effluent (POME): Win-win strategies toward better environmental protection. Biotechnol Adv 29: 124-141. https://doi.org/10.1016/j.biotechadv.2010.10.001

111. Isikgor FH, Becer RC (2015) Lignocellulosic Biomass: A Sustainable Platform for Production of Bio-Based Chemicals and Polymers. Polym Chem 6:4497-4559. https://doi.org/10. 4324/9781315079097-35

112. Obeng EM, Adam SNN, Budiman C, Ongkudon CM, Maas R, Jose J (2017) Lignocellulases: a review of emerging and developing enzymes, systems, and practices. Bioresour Bioprocess 4. https://doi.org/10.1186/s40643-017-0146-8

113. Sołowski G, Konkol I, Cenian A (2020) Production of hydrogen and methane from lignocellulose waste by fermentation. A review of chemical pretreatment for enhancing the efficiency of the digestion process. J Clean Prod 267:121721. https://doi.org/10.1016/j. jclepro.2020.121721

114. Ma J, Frear C, Wang Z-W, Yu L, Zhao Q, Li X, Chen S (2013) A simple methodology for rate-limiting step determination for anaerobic digestion of complex substrates and effect of microbial community ratio. Bioresour Technol 134:391-395. https://doi.org/10. 1016/j.biortech.2013.02.014
115. Minic Z, Thongbam PD (2011) The biological deep sea hydrothermal vent as a model to study carbon dioxide capturing enzymes. Mar Drugs 9:719-738. https://doi.org/10.3390/ md9050719

116. Liu S (2017) Bioprocess Engineering: Kinetics, Sustainability, and Reactor Design. Elsevier

117. Berg JM, Tymoczko JL, Stryer L (2002) Biochemistry Fifth Edition: International Version. W.H. Freeman

118. Litwack G (2018) Metabolism of Amino Acids

119. Hipkiss AR, Cartwright SP, Bromley C, Gross SR, Bill RM (2013) Carnosine: Can understanding its actions on energy metabolism and protein homeostasis inform its therapeutic potential? Chem Cent J 7:1-9. https://doi.org/10.1186/1752-153X-7-38

120. Den Besten G, Van Eunen K, Groen AK et al (2013) The role of short-chain fatty acids in the interplay between diet, gut microbiota, and host energy metabolism. J Lipid Res 54:2325-2340. https://doi.org/10.1194/jlr.R036012

121. Patakova P, Branska B, Sedlar K, Vasylkivska M, Jureckova K, Kolek J, Koscova P, Provaznik I (2019) Acidogenesis, solventogenesis, metabolic stress response and life cycle changes in Clostridium beijerinckii NRRL B-598 at the transcriptomic level. Sci Rep 9:1-21. https://doi.org/10.1038/s41598-018-37679-0

122. Amador-Noguez D, Brasg IA, Feng XJ, Roquet N, Rabinowitz JD (2011) Metabolome remodeling during the acidogenicsolventogenic transition in clostridium acetobutylicum. Appl Environ Microbiol 77:7984-7997. https://doi.org/10.1128/AEM. 05374-11

123. Ripoll V, Agabo-García C, Solera R, Perez M (2020) Modelling of the anaerobic semi-continuous co-digestion of sewage sludge and wine distillery wastewater. Environ Sci Water Res Technol 6: 1880-1889. https://doi.org/10.1039/d0ew00275e

124. Liu D, Sun Y, Li Y, Lu Y (2017) Perturbation of formate pathway and NADH pathway acting on the biohydrogen production. Sci Rep 7:1-8. https://doi.org/10.1038/s41598-017-10191-7

125. Fuller JR, Vitko NP, Perkowski EF, Scott E, Khatri D, Spontak JS, Thurlow LR, Richardson AR (2011) Identification of a lactatequinone oxidoreductase in Staphylococcus aureus that is essential for virulence. Front Cell Infect Microbiol 1:19. https://doi.org/10. 3389/fcimb.2011.00019

126. Schreiner ME, Eikmanns BJ (2005) Pyruvate:quinone oxidoreductase from Corynebacterium glutamicum: Purification and biochemical characterization. J Bacteriol 187:862-871. https://doi. org/10.1128/JB.187.3.862-871.2005

127. Kather B, Stingl K, Van Der Rest ME et al (2000) Another unusual type of citric acid cycle enzyme in Helicobacter pylori: The malate:quinone oxidoreductase. J Bacteriol 182:3204-3209. https://doi.org/10.1128/JB.182.11.3204-3209.2000

128. Maher MJ, Herath AS, Udagedara SR, Dougan DA, Truscott KN (2018) Crystal structure of bacterial succinate:quinone oxidoreductase flavoprotein $\mathrm{SdhA}$ in complex with its assembly factor SdhE. Proc Natl Acad Sci U S A 115:2982-2987. https://doi. org/10.1073/pnas. 1800195115

129. Lo YC, Chen CY, Lee CM, Chang JS (2010) Sequential darkphoto fermentation and autotrophic microalgal growth for highyield and $\mathrm{CO} 2$-free biohydrogen production. Int $\mathrm{J}$ Hydrogen Energy 35:10944-10953. https://doi.org/10.1016/j.ijhydene. 2010.07.090

130. Khan MZ, Nizami AS, Rehan M, Ouda OKM, Sultana S, Ismail IM, Shahzad K (2017) Microbial electrolysis cells for hydrogen production and urban wastewater treatment: A case study of Saudi Arabia. Appl Energy 185:410-420. https://doi.org/10.1016/j. apenergy.2016.11.005

131. Yu Z, Leng X, Zhao S, Ji J, Zhou T, Khan A, Kakde A, Liu P, Li X (2018) A review on the applications of microbial electrolysis cells in anaerobic digestion. Bioresour Technol 255:340-348. https:// doi.org/10.1016/j.biortech.2018.02.003 
132. Kadier A, Simayi Y, Abdeshahian P, Azman NF, Chandrasekhar K, Kalil MS (2016) A comprehensive review of microbial electrolysis cells (MEC) reactor designs and configurations for sustainable hydrogen gas production. Alexandria Eng J 55:427-443. https://doi.org/10.1016/j.aej.2015.10.008

133. Escapa A, Mateos R, Martínez EJ, Blanes J (2016) Microbial electrolysis cells: An emerging technology for wastewater treatment and energy recovery. from laboratory to pilot plant and beyond. Renew Sustain Energy Rev 55:942-956. https://doi.org/10. 1016/j.rser.2015.11.029

134. Kumar R, Singh L, Zularisam AW (2016) Exoelectrogens: Recent advances in molecular drivers involved in extracellular electron transfer and strategies used to improve it for microbial fuel cell applications. Renew Sustain Energy Rev 56:1322-1336. https:// doi.org/10.1016/j.rser.2015.12.029

135. Müller N, Worm P, Schink B, Stams AJM, Plugge CM (2010) Syntrophic butyrate and propionate oxidation processes: From genomes to reaction mechanisms. Environ Microbiol Rep 2: 489-499. https://doi.org/10.1111/j.1758-2229.2010.00147.x

136. Westerholm M, Moestedt J, Schnürer A (2016) Biogas production through syntrophic acetate oxidation and deliberate operating strategies for improved digester performance. Appl Energy 179: 124-135. https://doi.org/10.1016/j.apenergy.2016.06.061

137. Rousseau R, Etcheverry L, Roubaud E, Basséguy R, Délia ML, Bergel A (2020) Microbial electrolysis cell (MEC): Strengths, weaknesses and research needs from electrochemical engineering standpoint. Appl Energy 257:113938. https://doi.org/10.1016/j. apenergy.2019.113938

138. Cheng Y, Chong C, Lam M et al (2021) Holistic process evaluation of non-conventional palm oil mill effluent (POME) treatment technologies: A conceptual and comparative review. J Hazard Mater 409:124964. https://doi.org/10.1016/j.jhazmat.2020. 124964

139. Momirlan M, Veziroglu TN (2002) Current status of hydrogen energy. Renew Sustain Energy Rev 6:141-179. https://doi.org/ 10.1016/S1364-0321(02)00004-7

140. Boodhun BSF, Mudhoo A, Kumar G, Kim SH, Lin CY (2017) Research perspectives on constraints, prospects and opportunities in biohydrogen production. Int J Hydrogen Energy 42:2747127481. https://doi.org/10.1016/j.ijhydene.2017.04.077

141. Sekoai PT, Daramola MO (2015) Biohydrogen production as a potential energy fuel in South Africa. Biofuel Res J 2:223-226. https://doi.org/10.18331/BRJ2015.2.2.3

142. Shao W, Wang Q, Rupani PF, Krishnan S, Ahmad F, Rezania S, Rashid MA, Sha C, Md Din MF (2020) Biohydrogen production via thermophilic fermentation: A prospective application of Thermotoga species. Energy 197:117199. https://doi.org/10. 1016/j.energy.2020.117199

143. Kaushik A, Mona S (2017) Exploiting Biohydrogen Pathways of Cyanobacteria and Green Algae: An Industrial Production Approach. In: Biohydrogen Production: Sustainability of Current Technology and Future Perspective. Springer, New Delhi, pp 97113
144. Nagarajan D, Lee DJ, Chang JS (2019) Recent insights into consolidated bioprocessing for lignocellulosic biohydrogen production. Int J Hydrogen Energy 44:14362-14379. https://doi.org/10. 1016/j.ijhydene.2019.03.066

145. Kamaraj M, Ramachandran KK, Aravind J (2020) Biohydrogen production from waste materials: benefits and challenges. Int $\mathrm{J}$ Environ Sci Technol 17:559-576. https://doi.org/10.1007/ s13762-019-02577-z

146. Singh A, Rathore D (2017) Exploiting Biohydrogen Pathways of Cyanobacteria and Green Algae: An Industrial Production Approach. In: Biohydrogen Production: Sustainability of Current Technology and Future Perspective. Springer, India, pp 97-113

147. Balat H, Kirtay E (2010) Hydrogen from biomass - Present scenario and future prospects. Int J Hydrogen Energy 35:7416-7426. https://doi.org/10.1016/j.ijhydene.2010.04.137

148. Arimi MM, Knodel J, Kiprop A, Namango SS, Zhang Y, Geißen SU (2015) Strategies for improvement of biohydrogen production from organic-rich wastewater: A review. Biomass and Bioenergy 75:101-118. https://doi.org/10.1016/j.biombioe.2015.02.011

149. Soydemir G, keris-Sen UD, Sen U, Gurol MD (2016) Biodiesel production potential of mixed microalgal culture grown in domestic wastewater. Bioprocess Biosyst Eng 39:45-51. https://doi.org/ 10.1007/s00449-015-1487-3

150. Zhou Z, Yin X, Xu J, Ma L (2012) The development situation of biomass gasification power generation in China. Energy Policy 51:52-57. https://doi.org/10.1016/j.enpol.2012.05.085

151. Shuit SH, Tan KT, Lee KT, Kamaruddin AH (2009) Oil palm biomass as a sustainable energy source : A Malaysian case study. Energy 34:1225-1235. https://doi.org/10.1016/j.energy.2009.05. 008

152. Clean Power Indonesia - $700 \mathrm{kWp}$ Biomass Gasifier in Mentawai (Indonesia). https://www.ruralelec.org/project-case-studies/cleanpower-indonesia-700-kwp-biomass-gasifier-mentawai-indonesia

153. Fluidized Bed Biomass Gasification with Clay Catalyst

154. Heidrich ES, Edwards SR, Dolfing J, Cotterill SE, Curtis TP (2014) Performance of a pilot scale microbial electrolysis cell fed on domestic wastewater at ambient temperatures for a 12 month period. Bioresour Technol 173:87-95. https://doi.org/10. 1016/j.biortech.2014.09.083

155. Lin $\mathrm{C}, \mathrm{Wu} \mathrm{S}$, Lin $\mathrm{P}$ et al (2010) A pilot-scale high-rate biohydrogen production system with mixed microflora. Int $\mathrm{J}$ Hydrogen Energy 36:8758-8764. https://doi.org/10.1016/j. ijhydene.2010.07.115

156. Gottardo M, Micolucci F, Bolzonella D, Uellendahl H, Pavan P (2017) Pilot scale fermentation coupled with anaerobic digestion of food waste - Effect of dynamic digestate recirculation. Renew Energy 114:455-463. https://doi.org/10.1016/j.renene.2017.07. 047

Publisher's note Springer Nature remains neutral with regard to jurisdictional claims in published maps and institutional affiliations. 